\title{
Defects and crystallinity control of perovskite films for light- emitting diodes
}

Zhongcheng Yuan 


\title{
Defects and crystallinity control of perovskite films for light-emitting diodes
}

\author{
Zhongcheng Yuan
}

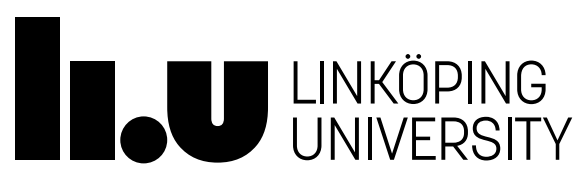

Biomolecular and Organic Electronics Division

Department of Physics, Chemistry and Biology (IFM)

Linköping University, SE-581 83 Linköping,

Sweden [2019] 
During the course of research underlying this thesis, Zhongcheng Yuan was enrolled in Agora Materiae, a multidisciplinary doctoral program at Linköping University, Sweden.

Copyright (C) Zhongcheng Yuan, 2019

Printed in Sweden by Liu-Tryck, Linköping, Sweden,2019

ISSN 0345-7524

ISBN 978-91- 7685-068-8 


\begin{abstract}
Metal halide perovskites are promising materials for the fabrication of costeffective and high-performance light-emitting diodes (LEDs), due to their solution processability, high photoluminescence quantum efficiencies (PLQEs) and excellent charge transport properties. Importantly, perovskite LEDs show ultra-pure emission color, which is better than that of the state-of-the-art quantum dot LEDs (QLEDs) and organic LEDs (OLEDs), demonstrating a bright application potential for realizing vivid natural colors display in the future.

In this thesis, we first incorporate natural molecules, e.g. deoxyribonucleic acid (DNA), to passivate $\mathrm{FAPbI}_{3}$ perovskite films. We notice that the existence of carbonyl and amide groups within DNA are important for efficient passivation of perovskite films. Combining the knowledge, we further introduce aminofunctionalized molecules into perovskite films and achieve significantly improved efficiency of $21.6 \%$, which is a record external quantum efficiency (EQE) of perovskite LEDs. We reveal that by weakening the hydrogen bond strength between passivation molecules and organic cations, the interaction between passivation amino groups and defects improves, contributing to more efficient passivation.

We also notice that the underlying substrates play important roles on the film quality of perovskite and the device performance of the ensuing LEDs. Here, we reveal that efficient deprotonation of the undesirable organic cations (Methylammonium $\left(\mathrm{MA}^{+}\right)$or Formamidinium $\left(\mathrm{FA}^{+}\right)$) by a metal oxide interlayer, e.g. $\mathrm{ZnO}$, with a high isoelectric point, is critical to promote the transition from intermediate phases to highly emissive perovskites. We reveal synergistic effects of precursor stoichiometry and interfacial reactions for highperformance perovskite LEDs, and establish useful guidelines for rational device optimisation. With the knowledge we obtain from the deprotonation process, we further push the EL emission from near-infrared (NIR) (around 800 $\mathrm{nm}$ ) region to deep red emission (around $700 \mathrm{~nm}$ ) via cation exchange process between cesium $\left(\mathrm{Cs}^{+}\right)$and $\mathrm{FA}^{+}$, which promotes enhanced crystallization of the perovskite films and devices performance simultaneously.
\end{abstract}


Intensive efforts in the perovskite community have pushed the EQEs of perovskite LEDs to over $20 \%$ for green, red and NIR emission region. However, it is still a long way to go before their practical applications. We believe that efficient control of both the defects and crystallinity of the perovskite films through rational materials development and interfacial modifications is important for the development of perovskite optoelectronic devices. In addition, both our findings on the perovskite film quality control are universal and provide insights to promote the development of perovskites (especially the hybrid ones containing organic components) for the applications of other optoelectronic devices.

Keywords: perovskite light emitting diodes, defects passivation, deprotonation, cation exchange, near-infrared emission 


\section{Populärvetenskaplig Sammanfattning}

Organiska-oorganiska hybrida perovskiter är lovande material för tillverkning av högpresterande ljusemitterande dioder (LED). Detta på grund av deras mycket höga fotoluminescenskvanteffektivitet samt utmärkta laddningstransporterande egenskaper. Framförallt uppvisar perovskita LED:er extremt höga färgrenhet, som är bättre än för de allra senaste oorganiska quantum dot-LED:erna, vilket visar att de har en ljus framtid och stor potential för naturlig färgåtergivning i framtiden.

Trots att den intensiva forskningen inom fältet har lett till en extern kvanteffektivitet på över $20 \%$ för gröna, röda och nära infraröda perovskita lysdioder är vägen till verklig applikaiton fortfarande lång. För det första är prestandan hos de blå perovskit-LED:erna fortfarande långt under den hos andra färger. För det andra utgör både materialstabiliteten och driftstabiliteten ett problem som måste lösas genom fortsatt utveckling av perovskitbaserade lysdioder.

I denna avhandling visar vi hur man använder naturlig deoxyribonukleinsyra (DNA) och organiska aminomolekyler för att passivera exponerade $\mathrm{Pb}^{2+}$ defekter i $\mathrm{FAPbI}_{3}$ perovskitfilmer. Vi uppnådde kraftigt förbättrad extern kvanteffektivitet på över 21\%, vilket är ett rekord hos perovskit-LED:er i skrivande stund. Vi noterar också att val av substrat spelar en mycket viktig roll för kvaliteten hos perovskitfilmer. Vi avslöjar att deprotoneringsprocessen av organiska katjoner (Formamidinium $\left(\mathrm{FA}^{+}\right)$) som utlöses av ett basiskt substrat, t.ex. $\mathrm{ZnO}$, bidrar till mycket förbättrad filmkvalitet och förbättrad prestanda. Våra resultat ger en djup förståelse för filmpassivering och tillväxtkontroll, vilket bidrar till att uppnå högpresterande och stabila perovskit-LED:er. 


\section{Acknowledgment}

I could never finish this thesis in four years without the kind support and endless help from my supervisors, colleagues and friends here in Linköping University.

Firstly, I would like to express my sincere gratitude to my supervisors Prof. Olle Inganäs and Dr. Feng Gao for offering me this precious opportunity so that I could be a member of this wonderful group. Thank you Olle, for the discussions we had. Your creative thinking and comments always deep our understanding on the research results and trigger new thoughts. Thank you, Feng, for the continuous support of my studies and countless individual meeting time you spent on my projects. Your patience, encouragement and immense knowledge make this journey different, exciting and interested. I also thank my mentor Prof. Per Hammarström for the interested discussions on my study and life here.

I would like to give my special thanks to Dr. Sai Bai, who offered lots of exciting ideas, constructive comments and suggestions on my projects. Your rich experience on material science and devices always make me calm when problems show up. In addition, I am also grateful for the delicious dishes you cooked and the cooking skills you taught. I owe you many thanks!

With a special mention to Prof. Fengling Zhang, Dr. Niclas Solin, Dr. Xiaoke Liu, Dr. Zhangjun Hu, Dr. Zhibo Yan, Dr. Deping Qian, Dr. Junjie Xie, Dr. Luis Ever Aguirre, Dr. Xiang Xu, Dr. Weidong Xu, Dr. Jun Lv, Dr. Feng Wang, and Dr. Chuanxiong Bao, I want to express my great appreciations to the help and insightful discussions in all these years.

My sincere thanks also go to my close friends in the Biorgel group: Heyong Wang, Hongling Yu, Chaoyang Kuang, Dr. Wanzhu Cai, Thomas Österberg, Dr. Jonas Bergkvist, Dr. Erica Zeglio, Dr. Fátima Ajjan, Max Karlsson, Yatao Zou, Weidong Cai, Yuming Wang, Fuxiang Ji, Huotian Zhang, Dr. Weihua Ning, Dr. Jian Qing, Ziyue Yi, Dr. Yan Xu, Dr. Jie Yang, Dr. Mei Yang, Jianwei Yu, Dr. Guanhaojie Zheng, Dr. Naresh Kumar Kumawat. Thank you for your full support and cooperation, and the delightful life we had together here in Linköping.

Collaborations always generate great ideas and sparks. A very special gratitude goes out to all my collaborators from Sweden, Italy, Singapore and China. I want to express special thanks to Prof. Jianpu Wang, who is so generous to share the experience on perovskites and light-emitting devices, and offers us a lot of constructive comments on our work and manuscripts. I thank Yanfeng Miao and Kang Pan for the help with photoluminescence measurements and the support you offered during my stay in Nanjing. 
I am also grateful to the following department faculty: Anna-Maria Uhlin, AnnCharlotte Svensson Holm, Chunxia Du, Ildiko Farkas, Thomas Lingefelt, who make my life, my work and my study here much easier than I thought.

Also, I thank Qingzheng Bian, Quanzhen Tao, Yuqing Huang, Yuxin Xia, Yong Yu, Shula Chen and Yuttapoom Puttisong, who are the senior members of the MacDonald team. The leisure afternoon and evenings we spent in the summertime are going to be a precious memory.

I express great thanks to my previous supervisor Prof. Baoquan Sun in Soochow University. Without your guidance and support, I could not never start this journey in science and research.

I want to thank all my friends and relatives, who make my holiday wonderful every time when I back to China.

Last but not least, I would like to thank my parents and my wife Tina Wang for your endless support and warm love in these years.

Zhongcheng Yuan

May 2019 at Linköping University 


\section{List of publications included in the thesis}

1. Deoxyribonucleic acid (DNA) molecular as a processing additive for efficient perovskite light emitting diodes

Z. Yuan, W. Cai, Z. Hu, W. Xu, Y. Miao, S. Bai, J. Wang, O. Inganäs \& F. Gao

Manuscript

2. Rational molecular passivation for high-performance perovskite light-emitting diodes

W. Xu, Q. Hu, S. Bai, C. Bao, Y. Miao, Z. Yuan, T. Borzda, A. J. Barker, E. Tyukalova, Z. Hu, M. Kawecki, H. Wang, Z. Yan, X. Liu, X. Shi, K. Uvdal, M. Fahlman, W. Zhang, M. Duchamp, J. Liu, A. Petrozza, J. Wang, L. Liu, W. Huang, F. Gao

Nature Photonics. 2019, 13, 418.

3. Room-temperature film formation of metal halide perovskites on n-type metal oxides: the catalysis of $\mathrm{ZnO}$ on perovskite crystallization

Z. Yuan, S. Bai, Z. Yan, JM. Liu \& F. Gao

Chem. Commun. 2018, 54, 6887.

4. Unveiling the synergistic effects of precursor stoichiometry and interfacial reaction for high-performance perovskite light-emitting diodes

Z. Yuan, Y. Miao, Z. Hu, W. Xu, C. Kuang, K. Pan, P. Liu, J. Lai, B. Sun, J. Wang, S. Bai \& F. Gao

Accepted in Nature communications

5. Deprotonation assisted mixed-cation perovskite crystallization for efficient light-emitting diodes

Z. Yuan, W. Xu, Z. Hu, Y. Miao, K. Pan, J. Wang, S. Bai \& F. Gao

Manuscript 


\section{Author contribution}

Paper 1: prepared DNA molecules dispersion, conducted synthesis of $\mathrm{ZnO}$ nanoparticles and devices fabrication, did most of the film characterizations, wrote the manuscript.

Paper 2: optimized the synthesis of $\mathrm{ZnO}$ nanoparticles and the device fabrication process, helped the revision process of manuscript.

Paper 3, 4: conducted the synthesis of $\mathrm{ZnO}$ nanoparticles, devices fabrication and did most of the characterizations, wrote the first draft, led the revision process of the manuscript.

Paper 5: conducted the synthesis of $\mathrm{ZnO}$ nanoparticles and devices fabrication and did most of the characterizations, wrote the manuscript. 


\section{List of publication not Included in the thesis}

\section{Research articles or communications}

1) Approximately 800 -nm-thick pinhole-free perovskite films via facile solvent retarding process for efficient planar solar cells

Z. Yuan, Y. Yang, Z. Wu, S. Bai, W. Xu, T. Song, X. Gao, F. Gao, and B. Sun.

ACS Appl. Mater. Interfaces 2016, 8, 50, 34446-34454.

2) Unravelling photostability of mixed cation perovskite films in extreme environment

J. Yang, Q. Hong, Z. Yuan, R. Xu, X. Guo, S. Xiong, X. Liu, S. Braun, Y. Li, J. Tang, C. Duan, M. Fahlman, Q. Bao

Adv. Opt. Mater. 2018, 6, 1800262.

3) Optical energy losses in organic-inorganic hybrid perovskite light-emitting diodes

X. Shi, Y. Liu, Z. Yuan, X. Liu, Y. Miao, J. Wang, S. Lenk, S. Reineke, F. Gao

Adv. Opt. Mater. 2018, 6, 1800667.

4) Oxygen-and water-induced energetics degradation in organometal halide perovskites

J. Yang, ${ }^{\#}$ Z. Yuan, ${ }^{\#}$ X. Liu, S. Braun, Y. Li, J. Tan, F. Gao, C.Duan, M. Fahlman, and Q. Bao (\# co-first author)

ACS Appl. Mater. \& Interfaces 2018, 10, 16225-16230.

5) Planar perovskite solar cells with long-term stability using ionic liquid additives

S. Bai, P. Da, C. Li, Z. Wang, Z. Yuan, F. Fu, X. Liu, N. Sakai, J. T. W. Wang, S. Huettner, S. Buecheler, M. Fahlman, F. Gao \& H. J. Snaith Accepted in Nature

6) Ultrafast long-range spin-funneling in solution-processed RuddlesdenPopper halide perovskites

D. Giovanni, J. W. M. Lim, Z. Yuan, S. S. Lim, M. Righetto, J. Qing, Q. Zhang, H. A. Dewi, F. Gao, S. G. Mhaisalkar, N. Mathews \& T. C. Sum Accepted in Nature communications

7) Efficient perovskite light-emitting diodes based on a solution-processed tin dioxide electron transport layer

H. Wang, H. Yu, W. Xu, Z. Yuan, Z. Yan, C. Wang, X. Liu, M. Fahlman, J. Liu, X. Liu and F. Gao 
J. Mater. Chem. C, 2018,6, 6996-7002.

8) Aligned and graded type-II ruddlesden-popper perovskite films for efficient solar cells

J. Qing, X. Liu, M. Li, F. Liu, Z. Yuan, E. Tiukalova, Z. Yan, M. Duchamp, S. Chen, Y. Wang, S. Bai, J. Liu, H. J. Snaith, Ch. Lee, T. Sum, F. Gao Adv. Energy Mater. 2018, 8, 1800185.

9) Efficient and tunable electroluminescence from in situ synthesized perovskite quantum dots

H. Yu, H. Wang, J. Zhang, J. Lu, Z. Yuan, W. Xu, L. Hultman, AA. Bakulin RH. Friend, J. Wang, X. Liu, F. Gao

Small, 2019, 0, 1804947.

10) Ultra-bright near-infrared perovskite light-emitting diodes with reduced efficiency roll-off

A. Giuri, Z. Yuan, Y. Miao, J. Wang, F. Gao, N. Sestu, M. Saba, G. Bongiovanni, S. Colella, C. E Corcione, G. Gigli, A. Listorti \& A. Rizzo Sci. Rep.2018, 8, 15496.

\section{Review articles}

1) Recent progress toward perovskite light-emitting diodes with enhanced spectral and operational stability

Y. Zou, Z. Yuan, S. Bai, F. Gao, and B. Sun

Materials Today Nano 2019, 100028.

2) Colloidal metal halide perovskite nanocrystals: synthesis, characterization, and applications

S. Bai, Z. Yuan and Feng Gao

J. Mater. Chem. C, 2016, 4, 3898-3904.

3) Metal doping/alloying of cesium lead halide perovskite nanocrystals and their applications in light-emitting diodes with enhanced efficiency and stability

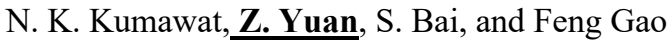

Isr. J. Chem.2019, DOI: 10.1002/ijch.201900031 


\section{Abbreviations}

\begin{tabular}{|c|c|}
\hline Abbreviation & Meaning \\
\hline (ATR) & Attenuated total reflectance \\
\hline OD & 0-dimensional \\
\hline $2 \mathrm{D}$ & 2-dimensional \\
\hline $3 \mathrm{D}$ & 3-dimensional \\
\hline $\mathrm{AX}$ & A-site cation halides (MAX, FAX or CsX) \\
\hline $\mathrm{BCP}$ & Bathocuproine \\
\hline CBM & Conduction band minimum \\
\hline CFL & Compact fluorescent lamp \\
\hline DMF & $\mathrm{N}, \mathrm{N}$-Dimethylformamide \\
\hline DMSO & Dimethyl sulfoxide \\
\hline EA & Ethanolamine \\
\hline EDX & Energy-dispersive X-ray \\
\hline EL & Electroluminescence \\
\hline $\mathrm{EQE}$ & External quantum efficiency \\
\hline FTIR & Fourier transform infrared spectroscopy \\
\hline FWHM & Full width at half maximum \\
\hline GBL & $\gamma$-Butyrolactone \\
\hline IPA & Iso-propanol \\
\hline IQE & Internal quantum efficiency \\
\hline ITO & Indium tin oxide \\
\hline LEDs & Light-emitting diodes \\
\hline $\mathrm{MAPbX}_{3}$ & Methylammonium lead tri-halide \\
\hline $\mathrm{MoO}_{3}$ & Molybdenum (VI) trioxide \\
\hline $\mathrm{NiO}_{\mathrm{x}}$ & Nickle oxide \\
\hline NPs & Nanoparticles \\
\hline OLEDs & Organic light-emitting diodes \\
\hline $\mathrm{PbX}_{2}$ & Lead halide $\left(\mathrm{PbI}_{2}, \mathrm{PbBr}_{2}\right.$ or $\left.\mathrm{PbCl}_{2}\right)$ \\
\hline PEDOT: PSS & Poly(3,4-ethylenedioxythiophene) polystyrene sulfonate \\
\hline PEI & Polyethylenimine \\
\hline PEIE & Polyethylenimine ethoxylated \\
\hline PFI & Perfluorinated ionomer \\
\hline PL & Photoluminescence \\
\hline PLQE & Photoluminescence quantum efficiency \\
\hline
\end{tabular}




\begin{tabular}{ll} 
QDs & Quantum dots \\
QLEDs & Quantum dot light-emitting diodes \\
QWs & Quantum wells \\
$\mathrm{SEI}$ & Secondary electrons imaging \\
$\mathrm{SEM}$ & Scanning electron microscopy \\
$\mathrm{SnO}_{2}$ & Tin oxide \\
$\mathrm{TCSPC}$ & Time-correlated single-photon counting \\
$\mathrm{TFB}$ & Poly[(9,9-dioctylfluorenyl-2,7-diyl)-co-(4,4'-(N-(4-sec- \\
& butylphenyl) diphenylamine) \\
$\mathrm{TiO}_{2}$ & Titanium oxide \\
$\mathrm{TOPO}_{\mathrm{UV}}$ & Trioctylphosphine oxide \\
$\mathrm{UV}-\mathrm{vis}$ & Ultraviolet-visible \\
$\mathrm{VBM}$ & Valance band maximum \\
$\mathrm{XPS}$ & X-ray photoelectron spectroscopy \\
$\mathrm{XRD}$ & X-ray diffraction \\
$\mathrm{ZnO}$ & Zinc oxide \\
\hline
\end{tabular}




\section{Table of Contents}

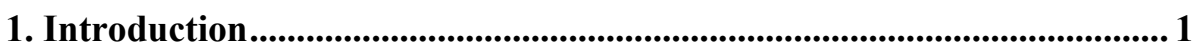

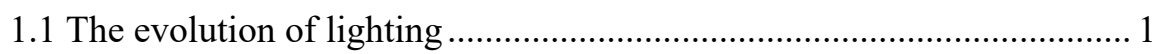

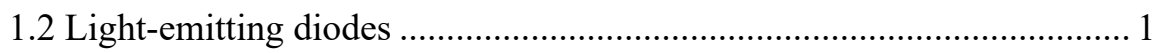

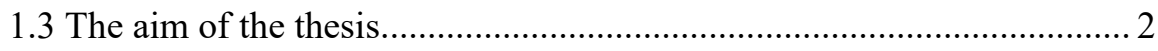

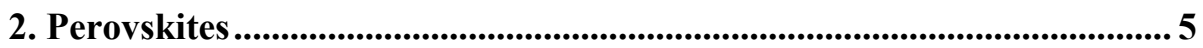

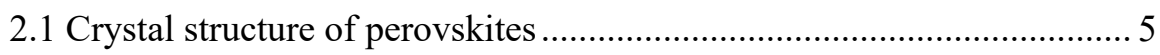

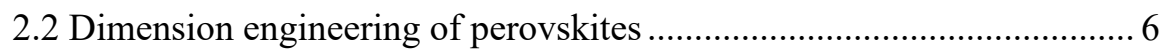

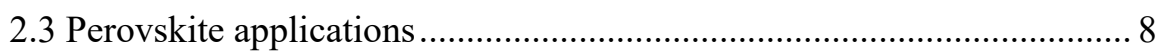

2.4 Defects and light emission of perovskites ........................................... 9

2.5 Fabrication of perovskite films.............................................................. 10

2.5.1 One-step spin-coating process. ................................................. 10

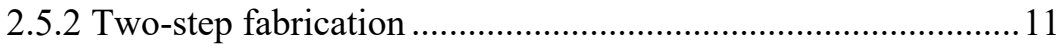

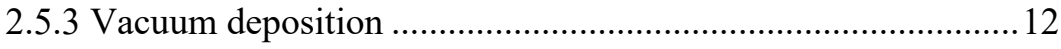

2.5.4 Large scale perovskite film deposition ..................................... 13

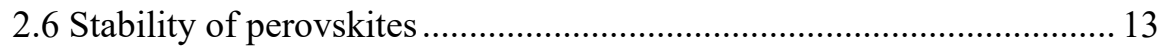

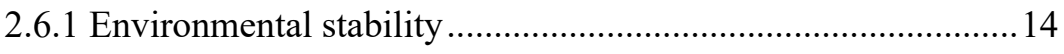

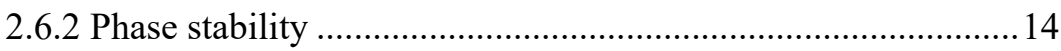

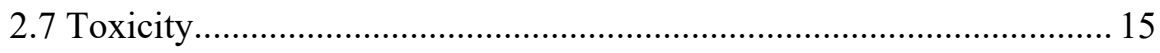

3. Perovskite LEDs...................................................................................... 17

3.1 Device structures of perovskite LEDs .................................................. 17

3.2 Working mechanism of perovskite LEDs ........................................... 18

3.3 Performance parameters of perovskite LEDs......................................... 19

3.4 Reliable measurements of perovskite LEDs......................................... 21

3.5 Fabrication procedures of perovskite LEDs .......................................... 24

3.6 Characterizations of perovksite films ................................................ 25

3.6.1 Time-correlated single-photon counting ...................................25

3.6.2 Photoluminescence quantum efficiency ...................................26

3.6.3 In-situ PL spectroscopy.......................................................28

3.6.4 Fourier transform infrared spectroscopy ..................................28 


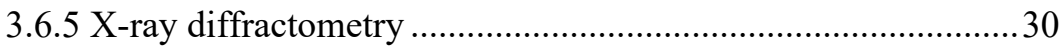

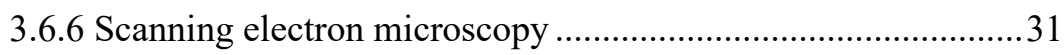

4. Defects passivation of perovskites ..................................................................... 33

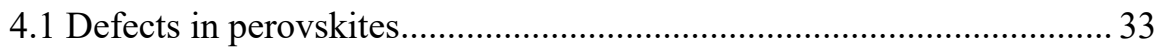

4.2 Charge carrier recombination dynamics in perovskites ......................... 34

4.3 Defect passivation of perovskite films ...................................................... 36

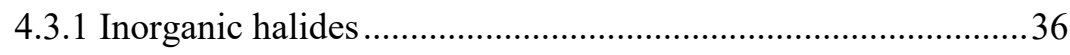

4.3.2 Organic passivation molecules. ................................................ 37

5. Control of the perovskite emissive layers .......................................................39

5.1 Morphology control of perovskite films.................................................. 39

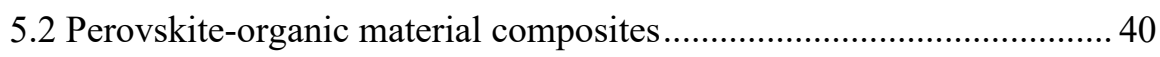

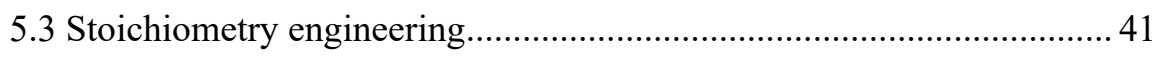

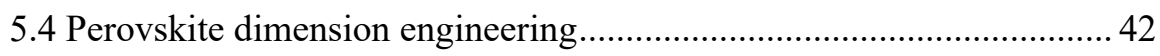

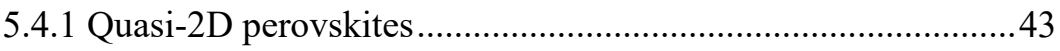

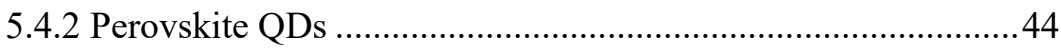

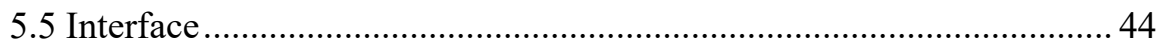

5.5.1 Interface and interface modifications.......................................4

5.5.2 Interface assisted deprotonation of organic cations ...................45

6. Conclusion and outlook ........................................................................................... 47

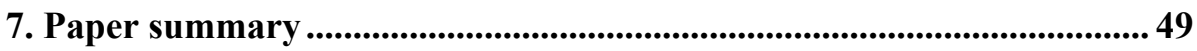

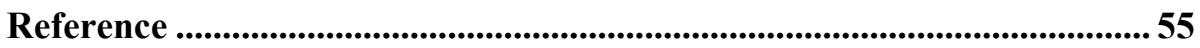




\section{Chapter 1}

\section{Introduction}

\subsection{The evolution of lighting}

Homo erectus is proved to be able to use and control the fire $\sim 100,000$ years ago, which was a turning point of human evolution. Fire provides warmth, a decent way to cook food, a protection against predators, and more importantly, it lights up the dark nights in the long history. ${ }^{[1]}$ In 1878, Thomas Alva Edison developed the first practical incandescent lamp with carbon filament, which made it possible to generate light from electricity with high and stable brightness. The inherent drawback, however, was that light generated from glows of the high-temperature filament leads to low power conversion efficiency, short lifetime and severe fire danger. Compact fluorescent lamps (CFLs), which make lighting dramatically energy-efficient than before, took the place of incandescent lamp in the 1980s. However, they contain a large amount of toxic mercury $(\mathrm{Hg})$, which complicates the recycling process and endangers the environment. Lighting technology based on solid-state light-emitting diodes (LEDs), which greatly improves the energy efficiency and operational lifetime and at the same time suppresses the heating within the devices, has shown great advances over the incandescent lamps and the CFLs. ${ }^{[2,3]}$ In addition, emission color of the LEDs could be easily tuned from ultra-violate to near-infrared (NIR) region, making them attractive for the applications in lighting, high-resolution flat panel displays, night version equipment, telecommunication, medical instruments etc. Considering threats from the energy crisis and the enhanced greenhouse effect, energy-efficient lighting and display technologies based on high-efficiency LEDs show promising future in daily life.

\subsection{Light-emitting diodes}

LEDs are electronic devices that convert electricity into light emission, commonly consisting of a stack of different function layers. The electroluminescence (EL) is generated from the radiative recombination of injected electrons and holes within the 
emission layer. The emitting color can be efficiently tuned by changing the bandgap of the light-emitting semiconductors. Conventional inorganic LEDs are commonly fabricated with metal-organic chemical vapor deposition (MOCVD) process to obtain emissive films with less defects on special substrates in order to achieve highperformance devices. ${ }^{[4]}$ However, the energy-intensive MOCVD process always requires high purity of the raw materials and expensive equipment. In addition, strong rigidity of the materials and the obtained devices limit their applications in flexible lighting and display technologies.

Organic light-emitting diodes (OLEDs) that developed in 1990s, featuring high efficiency, high brightness and flexibility, have now been widely used as screens of mobile phones, computers and televisions. However, the complex synthesis and difficult quality control process of the emissive materials hinder the low-cost access to these light emission technologies. Emerging quantum dot light-emitting diodes (QLEDs) with high color purities, ensuring a more vivid displays than OLEDs, have recently drawn dramatical attentions. However, fine control of the chemical synthesis of high-quality quantum dots (QDs) is still a key challenge for researchers and companies.

Metal halide perovskites with low trap densities within the films can be solution processed at relatively low processing temperature in large scale, either by blade-coating or printing. ${ }^{[5,6]}$ In addition, low-cost of the raw materials and their superior optoelectronic properties make metal halide perovskites very attractive for optoelectronic applications. ${ }^{[7]}$ These perovskites generate light emission with color purity that is comparable or higher than QDs, making them promising candidates for future high-quality displays and lighting source.

\subsection{The aim of the thesis}

Four years ago, when we started the research on perovskite LEDs, the filed was in its early stage. Low external quantum efficiencies (EQEs) of below $5 \%$ and poor operation lifetime of minutes dimmed their development prospects. ${ }^{[8,9]}$ However, during the past several years, we have witnessed dramatical improvement not only in the device performance, but also in the operational lifetime of perovskite LEDs. ${ }^{[10-12]}$ In addition, research on perovskite LEDs with different emitting colors have also achieved great success. The EQEs of perovskite LEDs with different emissive colors have been boosted to over $20 \%$ by different research groups. However, in-depth understanding of perovskite film growth, defect passivation and device working mechanism is still limited. In addition, effective strategies to improve the device operational lifetime are still missing. 
The aim of this thesis is to provide new understandings and efficient strategies on developing high-performance perovskite LEDs through efficient control of the perovskite films and interfaces. We provide answers to two fundamental and critical questions:

Firstly, how to achieve efficient passivation of the trap states in the perovskite films? We incorporate biomolecules and organic molecules with different functional groups into the perovskite films to efficiently heal the trap states. The much-decreased nonradiative recombination in the perovskite emitting layers leads to more efficient LEDs.

Secondly, we find that the buried substrates play important roles on the film crystallization process. Three commonly used n-type metal oxides: zinc oxide $(\mathrm{ZnO})$, tin oxide $\left(\mathrm{SnO}_{2}\right)$ and titanium oxide $\left(\mathrm{TiO}_{\mathrm{x}}\right)$ are used as the substrates in this thesis. We provide a comprehensive study on choosing suitable substrates to finely control the perovskite film quality, and ultimately, to achieve high-performance perovskite LEDs.

\section{The thesis is organized as below:}

In Chapter 2, we give a brief introduction on the fundamental of metal halide perovskites including crystal structures, material compositions, optoelectronic properties and material stability. We also discuss the development of lead-free perovskites on addressing the material toxicity issue.

In Chapter 3, we describe device structures, functional layer properties, working mechanism and commonly used fabrication processes of perovskite LEDs. We further discuss the device parameters, and characterizations of LEDs, all of which are prerequisites to study the device performance. At the end of this chapter, we summarize films characterization methods used in this thesis, including detailed information of the characterization mechanisms and the setup.

In Chapter 4, we discuss different types of trap states and their formation in perovskites. We further summarize the carrier recombination process in perovskite films. Passivation strategies developed in literature on improving the device performance of perovskite LEDs are also included in this chapter.

In Chapter 5, we review methods on efficient control of perovskite films. The summary is divided into five parts: 1) morphology control of perovskite films; 2) perovskite composites; 3) stoichiometry engineering; 4) perovskite dimension engineering; 5) interface. 
In Chapter 6, we summarise recent progress and challenges in perovskite LEDs and provide an outlook on the development of perovskite LEDs.

In Chapter 7, we highlight the key information in every paper included in this thesis. 
Perovskites

\section{Chapter 2}

\section{Perovskites}

\subsection{Crystal structure of perovskites}

Perovskites are a class of materials with a general formula of $\mathrm{ABX}_{3}$, which adopts the same structure as Calcium Titanate $\left(\mathrm{CaTiO}_{3}\right)$, where $\mathrm{B}$ represents the metal cation locating at the centre of the octahedral structure, and A stays at the corner of the octahedral with $X$ at six face centres, as shown in Figure 2.1a. ${ }^{[13,14]}$ There are large amounts of materials that meet the perovskite criteria with different compositions and various properties, demonstrating wide spread applications in piezoelectric and catalytic devices. ${ }^{[15,16]}$.

a)

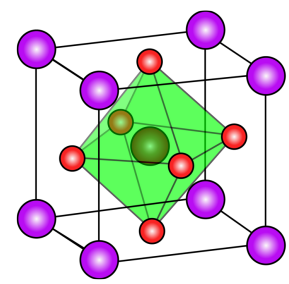

b)
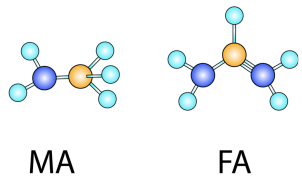

Figure 2.1 a) Brief diagram of perovskite crystal structure; b) structure of methylamine (MA) and formamidine (FA).

One of the most famous perovskite materials is the metal halide perovskites (hereafter referred to perovskites), which is mainly $\mathrm{Pb}$ or $\mathrm{Sn}$ based, with methylammonium $\left(\mathrm{MA}^{+}\right)$, formamidinium $\left(\mathrm{FA}^{+}\right)$or inorganic cesium $\left(\mathrm{Cs}^{+}\right)$as the $\mathrm{A}$ site cations and $\mathrm{Cl}^{-}, \mathrm{Br}^{-}$or $\mathrm{I}^{-}$ as the $\mathrm{X}$ site ions, as shown in Figure 2.1b. ${ }^{[17,18]}$ All the octahedrals connect with each other through corner sharing, forming continuous three-dimensional (3D) framework structure. In order to insert the $\mathrm{A}$ cations into the corner of the $\left[\mathrm{BX}_{6}\right]^{4-}$ octahedral framework, certain requirement needs to be met to form stable perovskites with cubic crystal structure, also known as the Goldschmidt's tolerance factor $(t)$ and octahedral factor $\mu$, as shown in the following equations, 


$$
\begin{gathered}
t=\frac{R_{A}+R_{X}}{\sqrt{2} \cdot\left(R_{B}+R_{X}\right)} \\
\mu=\frac{R_{B}}{R_{X}}
\end{gathered}
$$

where $R_{A}, R_{B}$ and $R_{X}$ are the ionic radii of $\mathrm{A}, \mathrm{B}$ and $\mathrm{X}$ ions by treating all of them as rigid spheres. We summarize the ion radii in Table 2.1. Only for conditions when $0.80<t<1.0$ and $0.40<\mu<0.90$, a cubic black phase perovskite structure can be achieved. $[19,20]$ Orthorhombic structured perovskite forms if $t$ is lower than 0.80 , while hexagonal perovskite structure forms if $t$ is higher than 1.0. Both cases result in the formation of yellow phase ( $\delta$-phase) in perovskite films. ${ }^{[21]}$

Table 2.1 Effective radii of commonly used cations and anions in metal halide perovskites.

\begin{tabular}{ccc}
\hline $\mathrm{R}_{\mathrm{A}}$ & $\mathrm{R}$ & $\mathrm{R}_{\mathrm{B}}$ \\
\hline $\mathrm{FA}^{+}(2.53 \AA)$ & $\mathrm{Pb}^{2+}(1.19 \AA)$ & $\mathrm{Cl}^{-}(1.81 \AA)$ \\
$\mathrm{MA}^{+}(1.80 \AA)$ & $\mathrm{Sn}^{2+}(1.18 \AA)$ & $\mathrm{Br}^{-}(1.96 \AA)$ \\
$\mathrm{Cs}^{+}(1.67 \AA)$ & & $\mathrm{I}^{-}(2.20 \AA)$ \\
\hline
\end{tabular}

\subsection{Dimension engineering of perovskites}

While the $\left[\mathrm{PbX}_{6}\right]^{4-}$ octahedral form a rigid structure for perovskite, they also limit the space for A-site cations. Instead, by inserting large sized cations between different octahedral layers, one can easily obtain two-dimensional (2D) layered perovskites with alternating organic-inorganic perovskite structures (quantum wells (QWs)), leading to wider tunability of the perovskite's family. ${ }^{[22]}$ As shown in Figure 2.2, since these large sized cations stay outside of the inorganic octahedral layers, there are minimum restrictions on their sizes. Here the formula of $2 \mathrm{D}$ perovskites is further modified to $\left(\mathrm{RNH}_{3}\right)_{2} \mathrm{~A}_{\mathrm{n}-1} \mathrm{~B}_{\mathrm{n}} \mathrm{X}_{3 \mathrm{n}+1}$, where $\mathrm{RNH}_{3}$ represents long chain cations and $\boldsymbol{n}$ is the number of the inorganic octahedral layers. ${ }^{[23]}$ Moreover, the hydrophobic long chain halides staying outside of the perovskite contribute to much improved devices operational stability. ${ }^{[23,24]}$ When the inorganic layer thickness is narrowed to below the Bohr radius, quantum confinement effects become an important phenomenon that promotes a blue shift of the photoluminescence (PL) emission. In addition, the 2D perovskite structure 


\section{Perovskites}

increases the exciton binding energy, which further improves the radiative recombination rate in the material, making it more suitable for light-emitting devices. ${ }^{[25]}$

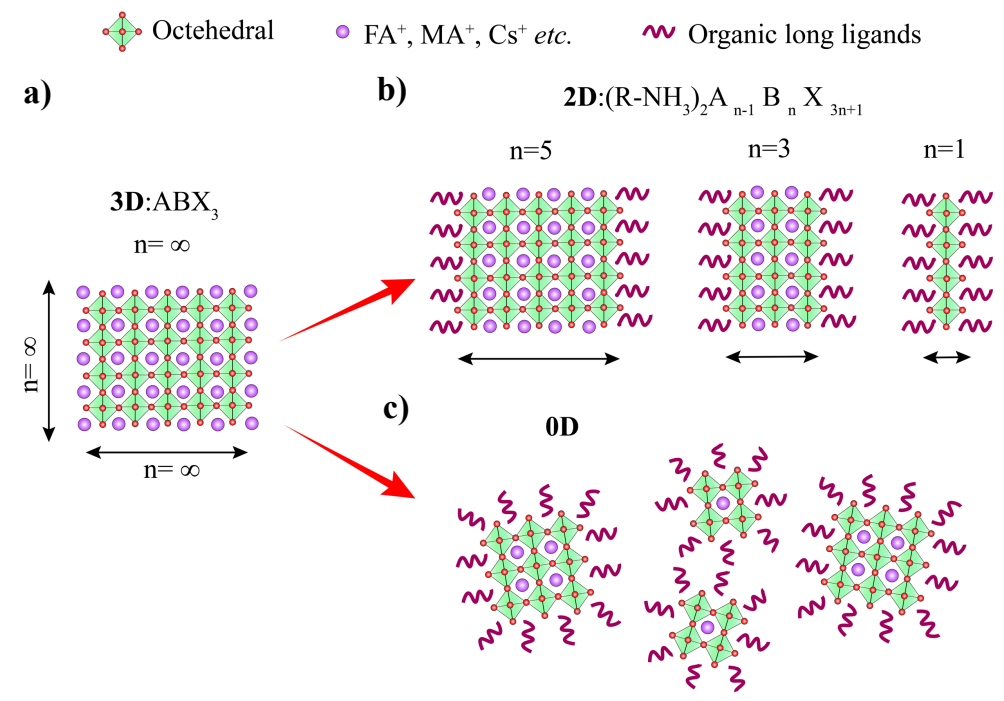

Figure 2.2 Perovskite dimensional engineering: $a-b)$ from 3D to 2D layered perovskite; $a-c)$ 3D to $0 \mathrm{D}$ perovskite.

Further narrowing down the perovskite dimension, one can obtain the one-dimensional (1 D) perovskite nanowire (NWs). However, the applications of perovskite NWs are relatively limited since they tend to form aggregations in colloidal solution. ${ }^{[26]}$

While obtaining colloidal QDs via wet chemistry synthesis is an effective strategy to decrease the traps states and increase the PLQEs of conventional inorganic materials, e.g. lead (II) sulfide ( $\mathrm{PbS}$ ) and cadmium selenide (CdSe). ${ }^{[27,28]}$ Further decreasing the dimensionality of typical perovskite crystals to zero-dimensional $(0 \mathrm{D})$ perovskite QDs shows great potential to fabricate high-performance perovskite LEDs (Figure 2.2). A greatly improved PLQE to unity can be achieved due to the much-enhanced exciton binding energy and well passivated defects. In addition, a very narrow full width at half maximum (FWHM) of the QDs emission below $30 \mathrm{~nm}$ can be observed. ${ }^{[29,30]}$ Both the high PLQEs and narrow FWHM of the emission make perovskite QDs extremely promising in low-cost lighting and display applications. 


\section{Perovskites}

\subsection{Perovskite applications}

The successful application of these perovskite materials in photovoltaic devices has pushed the power conversion efficiency (PCE) to $24.2 \%$, which outperforms all the other kinds of thin film solar cells. ${ }^{[31]}$ Along with the high efficiencies, the stability of perovskite solar cells also shows dramatical progress. Currently, the state-of-the-art perovskite solar cells can work in harsh environment for over thousands of hours without showing obvious efficiency decay. ${ }^{[23]}$ In addition, due to the unique properties of high PLQEs, high charge mobilities and color purity etc, perovskites have also achieved great advances in LEDs. Up till now, the EQEs of perovskite LEDs have been improved to $20 \%$ for emission in green, red and NIR regions. ${ }^{[10,11,32]}$

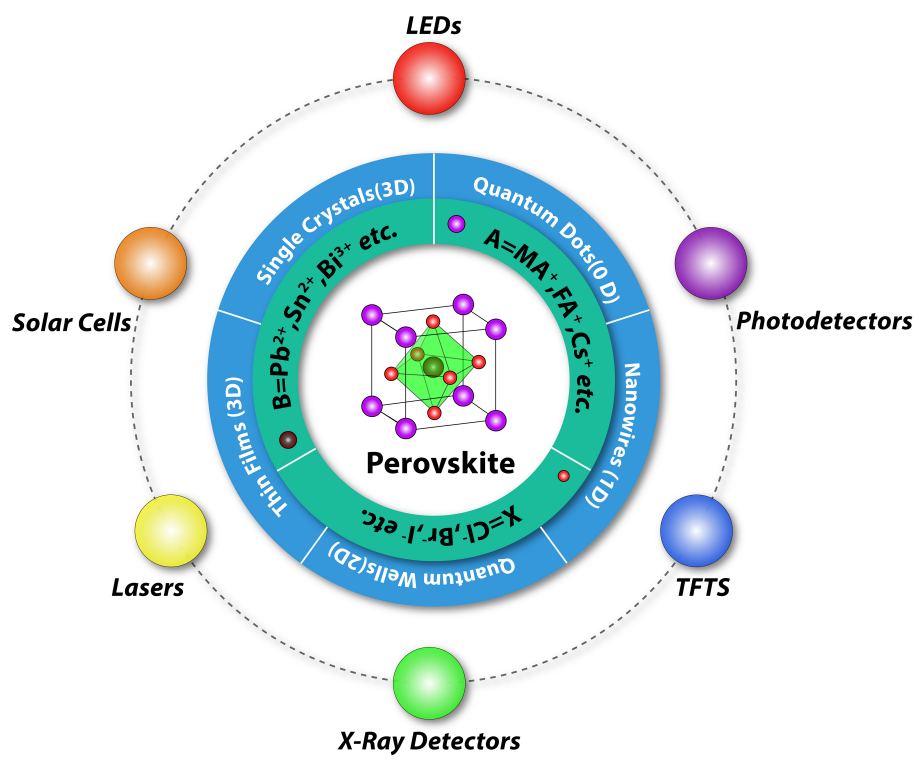

Figure 2.3 Applications of perovskites in electronic device.

Apart from solar cells and LEDs, perovskites also show outstanding performance in Xray detections. ${ }^{[33]}$ By using $\mathrm{CsPbBr}_{3}$ QDs as scintillators in X-ray imagers, the X-ray does needed for imaging decreases more than 400 times than conventional CsI: Tl based imagers. ${ }^{[33]}$ This unique performance makes X-ray imaging in medical area much safer than before.

In addition, as shown in Figure 2.3, metal halide perovskites have also demonstrated wide applications in lasers, photodetectors, chemical sensors and Thin-film transistor (TFTs) etc. ${ }^{[34-36]}$ 


\section{Perovskites}

\subsection{Defects and light emission of perovskites}

Defect tolerance is one of the most unique properties of metal halide perovskites, which contributes to more efficient radiative recombination and much enhanced PLQEs. This special defect tolerance is due to the molecular orbital condition in perovskites, as shown in Figure. 2.4a. Here we use the $\mathrm{MAPbI}_{3}$ perovskite as an example. The bandgap energy is determined by the position of the conduction band minimum (CBM) and valance band maximum (VBM). The CBM is determined by antibonding states of $\mathrm{Pb}(6 \mathrm{p})$ and $\mathrm{I}(5 \mathrm{p})$ orbitals, with $\mathrm{Pb}(6 \mathrm{p})$ playing a dominant role. The VBM is formed by the antibonding hybridization of $\mathrm{Pb}(6 \mathrm{~s})$ and I (5p) orbitals, with I (5p) making more contribution. ${ }^{[37]}$ Accordingly, the band edge states of conduction band (CB) and valance band (VB) are highly influenced by $\mathrm{Pb}$ and halides. The vacancies of these atoms only form traps states within $\mathrm{CB}$ or VB, leaving a clear bandgap free of traps states. These shallow traps show minimum effects on the PL emission of perovskite because they will not lead to serious non-radiative recombination. However, for other conventional inorganic materials, e.g. gallium arsenide (GaAs), the vacancies of atoms result in the formation of nonbonding orbitals that stay within materials bandgap, forming deep traps and deteriorating the PL emission performance dramatically (Figure 2.4b). ${ }^{[38]}$

a)

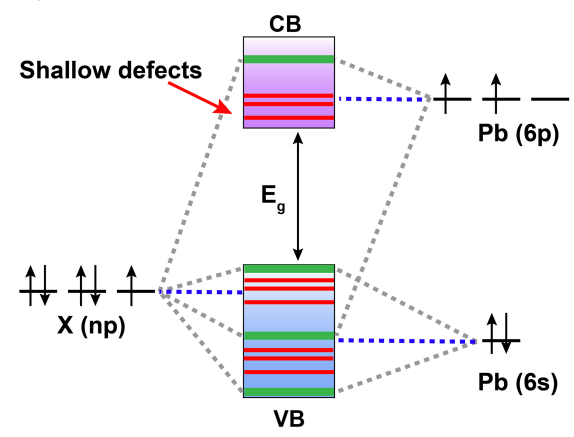

b)

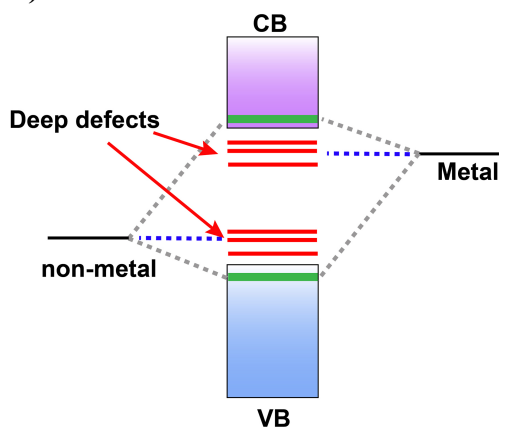

Figure 2.4 Molecular orbital diagram of a) metal halide perovskites and b) conventional inorganic semiconductors materials (e.g. GaAs).

Since the CBM and VBM are more relevant to the $\mathrm{Pb}(6 \mathrm{p})$ and I (5p) orbitals, halide composition engineering is a very efficient way to tune the bandgap of perovskites, generating perovskites with different emission color. By changing the halides from I (5p) to $\mathrm{Br}(4 \mathrm{p})$ and $\mathrm{Cl}(3 \mathrm{p})$, the decreasing $p$ orbital energy of halides leads to enlarged bandgap of perovskites. ${ }^{[39]}$ For example, the PL emission of perovskites can be continuously tuned from red $\left(\mathrm{CsPb}_{3}, \sim 700 \mathrm{~nm}\right)$ to purple $\left(\mathrm{CsPbCl}_{3}, \sim 400 \mathrm{~nm}\right)$ region 


\section{Perovskites}

by tuning the halide composition from pure I to pure $\mathrm{Cl}$ (Figure 2.5). ${ }^{[40,41]}$ In addition, engineering A-site and B-site cations also changes the bandgap of perovskite. The maximum range of halide perovskite emission currently can be tuned from $\sim 1.17 \mathrm{eV}$ $\left(\mathrm{FAPb}_{\mathrm{x}} \mathrm{Sn}_{(1-\mathrm{x})} \mathrm{I}_{3}\right)$ to $\sim 3.1 \mathrm{eV}\left(\mathrm{CsPbCl}_{3}\right)_{.}{ }^{[5,42]}$

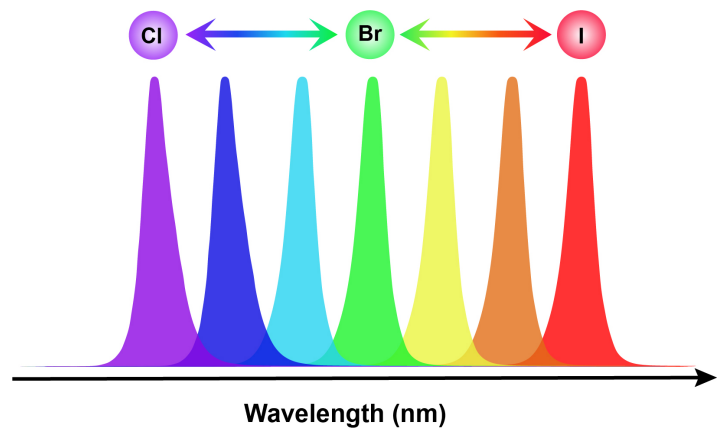

Figure 2.5 PL emission spectra of lead-based perovskite with different halide compositions.

\subsection{Fabrication of perovskite films}

Preparing high quality and uniform perovskite films is a prerequisite to achieve highperformance perovskite optoelectronic devices. There are a number of different wellinvestigated methods in the perovskite community. It is well acknowledged that different deposition methods often generate perovskite films with varied morphology, further affecting crystal qualities of the obtained perovskite films. In addition, these deposition methods also influence optoelectronic properties of the resulting films, especially the charge carrier dynamics and trap state densities, both of which play important roles on the performance of perovskite optoelectronic devices. We summarize these methods for perovskite films preparation as below.

\subsubsection{One-step spin-coating process.}

Among all the fabrication methods, one-step spin-coating process is the most straightforward way to obtain perovskite films. The precursor solution is prepared by simply mixing lead halides $\left(\mathrm{PbX}_{2}\right)$ and A-site cation halides (AX, e.g. MAX, FAX or $\mathrm{CsX}$ ) in a polar solvent like, N,N-Dimethylformamide (DMF), Dimethyl sulfoxide (DMSO) and $\gamma$-Butyrolactone (GBL). ${ }^{[13]}$ As shown in Figure 2.6, by spin-coating perovskite precursor solution directly on substrates and then annealing the films at a certain temperature, one can easily obtain perovskite films. However, due to the high boiling point of the used solvents for precursor solution, the spin-coating process leaves a relatively long-time window for perovskite components to aggregate, resulting in non- 


\section{Perovskites}

uniform film morphology with large-size domains. In order to suppress the time window to a shorter time range, an anti-solvent method was introduced (also shown in Figure 2.6). ${ }^{[43]}$ Basically, a solvent (toluene, chlorobenzene (CB) etc.) that is miscible with the precursor solvent but has poor solubility towards the perovskite components is chosen. It is conducted by pouring the solvent on top of the precursor film after starting the spincoating process a few seconds. After spin-coating process, a compact and smooth perovskite film is obtained. This process helps to extract the precursor solvent from the films and accelerate the crystallization of perovskite components. And consequently, it decreases the crystal sizes of the perovskite grains, generating a more uniform film morphology. ${ }^{[43,44]}$ Besides, this anti-solvent methods could also be operated by purging high flow nitrogen $\left(\mathrm{N}_{2}\right)$ on the film surface after starting the spin-coating process. ${ }^{[45]}$

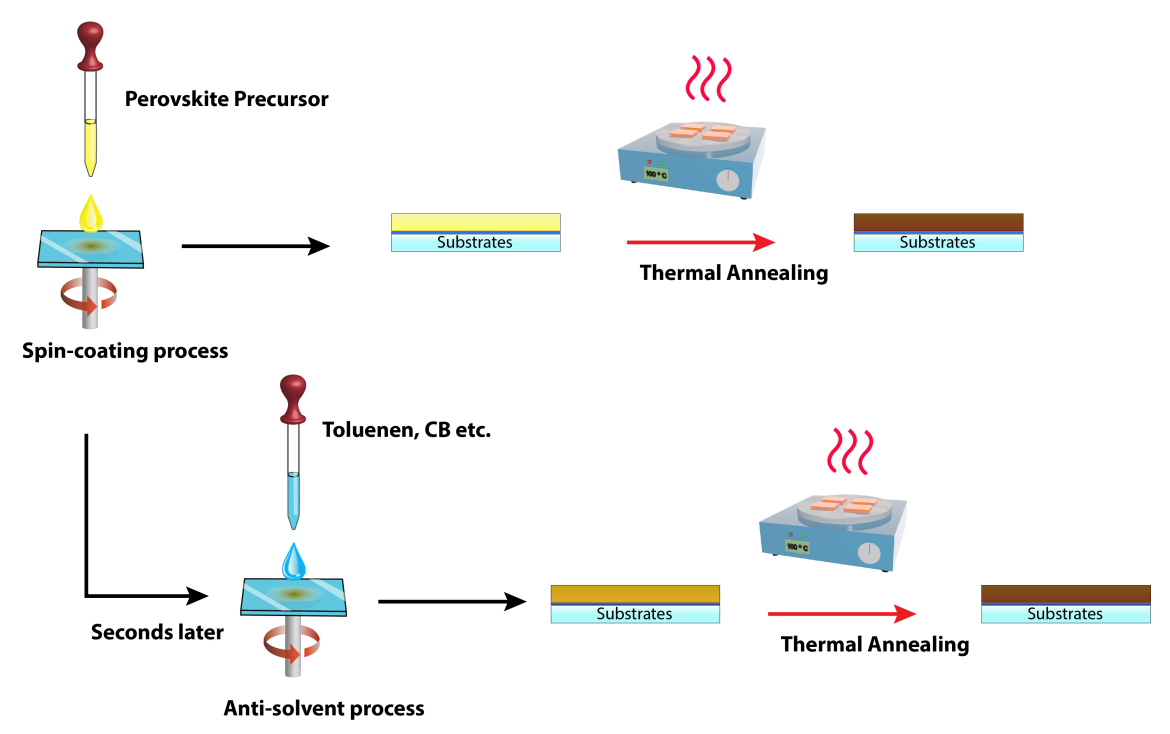

Figure.2.6 Schematic illustration of the one-step method for perovskite films deposition.

\subsubsection{Two-step fabrication}

Another widely used method for perovskite film deposition is a two-step process, which is depicted in Figure 2.7. This process involves two steps: firstly, spin-coating of the lead halide $\left(\mathrm{PbX}_{2}\right)$ film and the whole substrate is then immersed into a diluted MAX or FAX solution (commonly in iso-propanol (IPA)) for $30 \mathrm{~s}-2 \mathrm{~min}$. After thermal annealing, a uniform perovskite film is obtained. ${ }^{[46]}$ The thickness of $\mathrm{PbX}_{2}$ film, the concentration and temperature of MAX or FAX solution all influence the final perovskite film morphology and quality. Since this film deposition process is not compatible with largescale production, another modified two-step process is developed. Instead of immersing 


\section{Perovskites}

the substrates into the solution, MAX or FAX solution is spin-coated on top of the $\mathrm{PbX}_{2}$ film. During the thermal annealing process, MA or FA cations penetrate into $\mathrm{PbX}_{2}$ matrix and form the perovskite structure. Since the inorganic $\mathrm{PbX}_{2}$ layer is very dense, the penetration depth of FA or MA is quite limited, resulting in residual of un-reacted $\mathrm{PbX}_{2}$. In order to fully transform the compact $\mathrm{PbX}_{2}$ into perovskite structure, a 'solvent annealing' process was developed. During the thermal annealing process, the substrates were heated in a solvent vapor (e.g. DMF) to achieve much bigger perovskite grains (up to several micrometres). ${ }^{[4]}$ Alternatively, this second step can also be accomplished by a vapour-assisted solution process. ${ }^{[48]}$ By annealing the inorganic $\mathrm{PbX}_{2}$ layer in a MAX or FAX vapor, the reaction speed between $\mathrm{PbX}_{2}$ and organic halides is decreased, resulting in uniform film morphology, and consequently a high reproducibility in device fabrication.
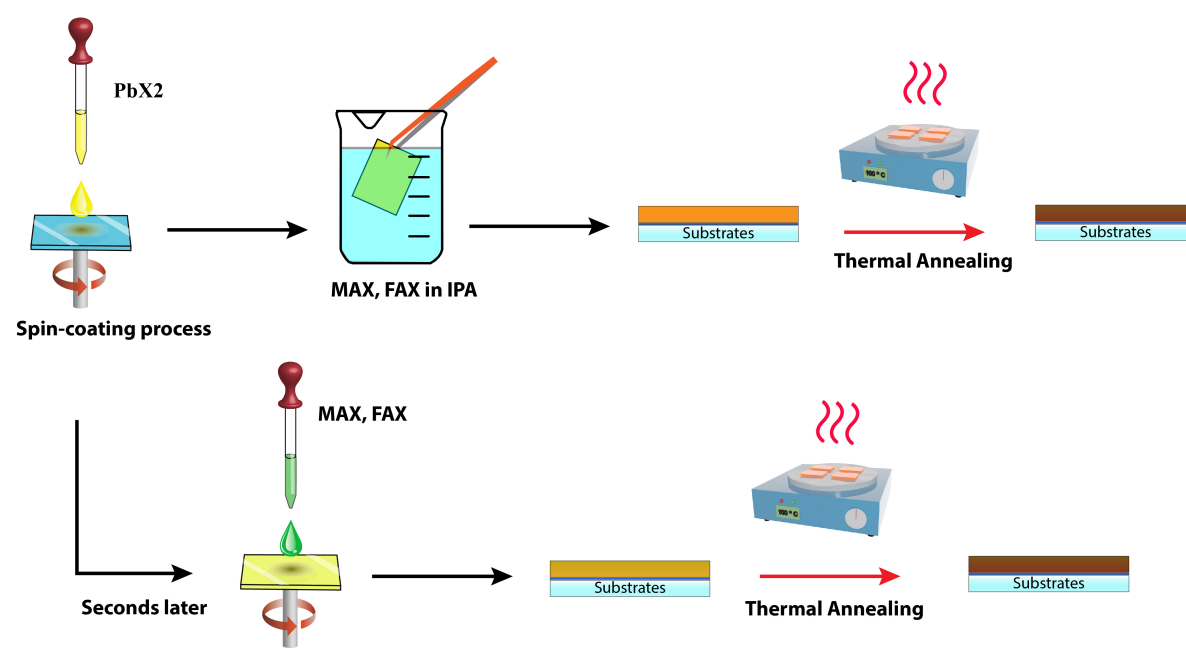

Figure 2.7 Schematic illustration of two-step method for perovskite films deposition

\subsubsection{Vacuum deposition}

Vacuum deposition is efficient to deposit perovskite film with uniform film morphology, precisely controlled material composition and film thickness, and shows potential advantages in practical applications. In addition, since no solvent is involved in this process, it is an ideal way to study the pristine film formation process by excluding the effects of the precursor solvents.

The vacuum deposition is often operated in a 'dual sources' way. In the setup, two heating sources are needed in a vacuum chamber (below $10^{-5} \mathrm{mbar}$ ), as shown in Figure 


\section{Perovskites}

2.8. By evaporating $\mathrm{PbX}_{2}$ and MAX (or FAX) simultaneously in two different heating sources with different rates, uniform perovskite films can be achieved. ${ }^{[49]}$ This method forms high quality perovskite film with greatly improved morphology as compared to one-step methods. However, the high cost for evaporation instruments and low production rates hinder the wide application of this vacuum deposition technique.

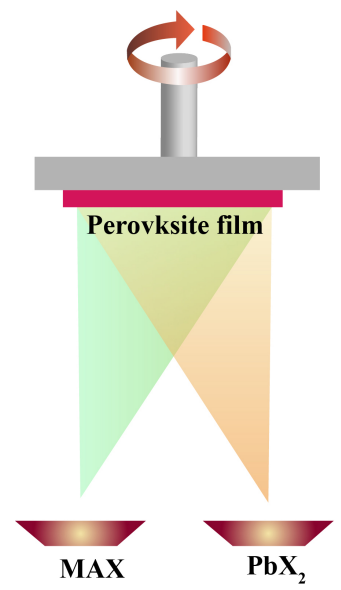

Figure 2.8 Diagram of dual-source vacuum deposition.

\subsubsection{Large scale perovskite film deposition}

Apart from the three methods mentioned above, printing is also a thriving area that researchers are interested in due to its advantage in producing large area perovskite films in a high speed. Different printing technologies have been developed for large area film deposition, e.g. inject printing, slot-diet coating, blade coating, screen printing, and even roll-to-roll production. ${ }^{[5,50]}$ These methods not only increase the film production dramatically, but also can obtain high quality films, showing a great potential for future fabrication of solar cells and LEDs.

\subsection{Stability of perovskites}

Stability (environmental stability and phase stability) of perovskites is one of the most critical issues that limit their wide applications. The soft ionic nature of perovskite lattice originates from the weak ionic interaction between perovskite compositions, making them vulnerable to extrinsic environment. In addition, the unmatched sizes of cations and halide ions lead to unstable phase of perovskites. 


\section{Perovskites}

\subsubsection{Environmental stability}

Among all factors that affect the chemical stability of perovskite, moisture, heat, ion migration, light illumination and oxygen are the most important ones. ${ }^{[51,52]}$ Especially in the perovskite LEDs, the heat generated during device operation and the ion migration under electrical field are vital issues that impede the improvement of device performance and operational stability. ${ }^{[53,54]}$

As described in previous literature, the temperature at the junction area of perovskite LEDs can exceed $40{ }^{\circ} \mathrm{C}$, when operating at a current density of $40 \mathrm{~mA} \mathrm{~cm}{ }^{-2}$. ${ }^{[53]}$ This high temperature leads to fast degradation of perovskites. Strategies like choosing more stable perovskite emitters are preferred to achieve stable perovskite LEDs. Besides, decreasing the thickness of perovskite emission layers show positive effects on device working stability since the thick emission layer is not good for fast heat dissipation. ${ }^{[53]}$ Ion migration under the electrical field is another important factor that degrades perovskites in LEDs. Previous results have shown that halides migration only need low activation energy (below $0.6 \mathrm{eV}$ ) to happen. ${ }^{[55]}$ The ion migration generates defects in perovskites and degrades perovskite LEDs in long time operation mode. ${ }^{[56]}$

In addition, continuous research efforts have revealed that the poor chemical stability of perovskites mainly result from the organic cations. Replacing organic cations with inorganic ones (e.g. $\mathrm{CsPbX}_{3}$ ) promote much improved chemical stability. ${ }^{[57,58]}$

\subsubsection{Phase stability}

Apart from the environmental stability of perovskite, phase stability is another aspect that needs to be considered when utilizing perovskite in electronic devices. The unmatched sizes of $\mathrm{Pb}$ and cation halides result in titled octahedral arrangement, leading to perovskite phase transition. Representative unstable perovskite is $\mathrm{CsPb}_{3}$ and $\mathrm{FAPbI}_{3}$, while the former one has a $t<0.8$ and the latter one has $t$ higher than 1.0. Consequently, $\mathrm{CsPbI}_{3}$ and $\mathrm{FAPbI}_{3}$ tend to form orthorhombic phase (yellow phase, $\delta_{o}$-phase) and

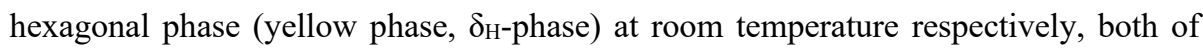
which are not photo-active phases. Although cubic phase (black phase, $\alpha$-phase) $\mathrm{CsPbI}_{3}$ and $\mathrm{FAPbI}_{3}$ can be achieved by relative high-temperature thermal annealing process, the spontaneous transition from $\alpha$-phase to $\delta$-phase cannot be avoided when cooling down to the room temperature. ${ }^{[57]}$

The non-ideal tolerance factor $(t)$ can be tuned to the phase stable region by cation or halides engineering, which balances the strain within perovskite crystals. ${ }^{[17,21,59]}$ In addition, narrowing the $\mathrm{CsPbI}_{3}$ and $\mathrm{FAPbI}_{3}$ perovskite size is another effective way to stabilize the $\alpha$-phase, e.g. forming $2 \mathrm{D}$ or $0 \mathrm{D}$ perovskites. ${ }^{[58,60]}$ 


\section{Perovskites}

In addition, tuning the emission color of perovskites with introducing mixed halide composition ( $\mathrm{Br}: \mathrm{I}$ or $\mathrm{Br}: \mathrm{Cl}$ ) is the most promising way to achieve blue and red perovskite LEDs. ${ }^{[29]}$ However, this strategy brings problem of phase separation upon light illumination and under electric field, generating $\mathrm{I}$ and $\mathrm{Br}$ (or $\mathrm{Cl}$ and $\mathrm{Br}$ ) rich clusters at grain surface. ${ }^{[61,62]}$ This phase separation leads to unstable emission spectra and serious trap-assisted recombination ${ }^{[63]}$ Further strategy on stabilizing the EL emissoin spectra of mixed hadile perovksites is still necessary.

\subsection{Toxicity}

Although $\mathrm{Pb}$ based perovskites have shown great potential in photovoltaics and various optoelectronic devices, the toxicity of $\mathrm{Pb}$ within perovskites remain a concern for their practical applications. ${ }^{[64]}$ In order to overcome the toxicity problem of perovskite materials, replacing $\mathrm{Pb}$ with alternative low-toxic or no-toxic elements while preserving the excellent optoelectronic properties of perovskites is a hot research topic.

Tin ( $\mathrm{Sn}$ ) based perovskites are promising candidates for $\mathrm{Pb}$ free materials and devices, especially for solar cells, since they have smaller bandgap down to $\sim 1.17 \mathrm{eV} .^{[42]}$ However, the notorious poor stability of $\mathrm{Sn}^{2+}$ hinders the preparation of high quality and stable perovskite devices. Besides, it is suggested that $\mathrm{Sn}^{2+}$ shows similar toxicity as that of $\mathrm{Pb}^{2+} \cdot{ }^{[65]}$ Further research on replacing $\mathrm{Pb}$ with bismuth (Bi) or antimony ( $\mathrm{Sb}$ ) result in the formation of low dimensional perovskites, commonly with a chemical formula of $\mathrm{A}_{3} \mathrm{~B}_{2} \mathrm{X}_{9}$. The bioctahedral $\left(\mathrm{B}_{2} \mathrm{X}_{9}\right)^{3-}$ clusters are surrounded by $\mathrm{A}$ site cations, which isolate the bioctahedral from each other, forming a $0 \mathrm{D}$ perovskite structure with poor charge carrier mobility. ${ }^{[66,67]}$ Therefore, although both Bi and Sb show much decreased toxicity to human beings and environment, the poor electronic properties of these materials limit their applications in optoelectronic devices.

Another alternative category of lead-free perovskites, with preserved corner sharing perovskite structure, is called 'double perovskite' (as depicted in Figure 2.9). Double perovskites are prepared by replacing two $\mathrm{Pb}^{2+}$ cations with a monovalent metal cation $\mathrm{M}^{+}$and a trivalent metal cation $\mathrm{N}^{3+} \cdot{ }^{[68]}$ In addition, rich choices of $\mathrm{M}$ and $\mathrm{N}$ metal cations in the periodic table make this double perovskite family a rich source for various applications. 


\section{Perovskites}

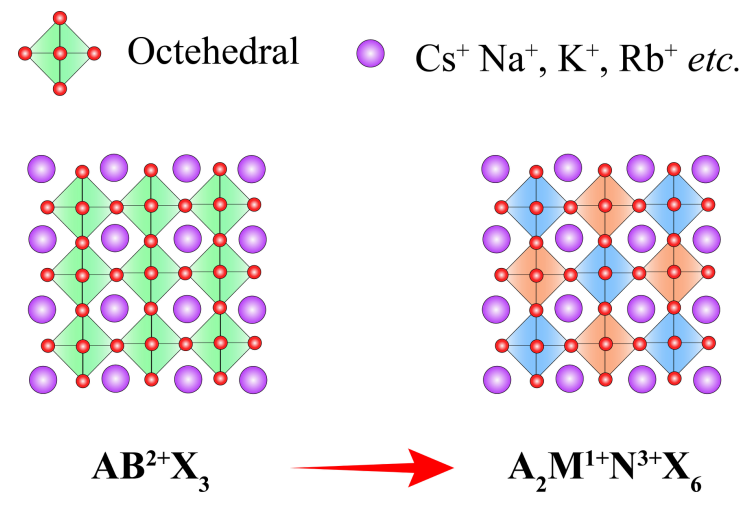

Figure 2.9 crystal structure diagram of conventional perovskite $\left(\mathrm{ABX}_{3}\right)$ and double perovskite.

Although according to theoretical calculation there are over thousands of double perovskites, only a few of them can be synthesised now. Two of the most representative double perovskites are $\mathrm{Cs}_{2} \mathrm{AgBiBr}_{6}$ and $\mathrm{Cs}_{2} \mathrm{AgInCl}_{6} .{ }^{[69,70]}$ Due to the inorganic nature of double perovskites, they also show decent material stability against moisture and oxygen, ensuring a bright application future. ${ }^{[71]}$ 


\section{Chapter 3}

\section{Perovskite LEDs}

\subsection{Device structures of perovskite LEDs}

Perovskite LEDs fabricated in this thesis are prepared in a sandwich structure, which adopts from well-studied OLEDs and QLEDs. ${ }^{[2,72]}$ Planar structured LED devices are commonly fabricated in a multi-layered structure, with the perovskite light-emitting layer sandwiched between a hole injection layer (HIL) and an electron injection layer (EIL). One of the major advantages of the perovskite LEDs is that all the emitting layers and the charge carrier injection layers can be solution processed in simple ways, indicating a cost-effective potential for device fabrication.

a)

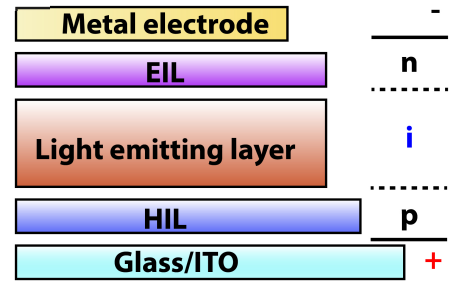

Conventional structure (p-i-n) b)

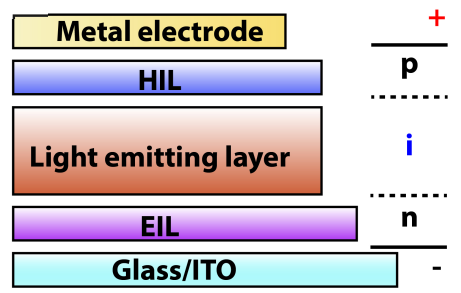

Inverted structure (n-i-p)

Figure 3.1 Illustration of device geometries: a) $p-i-n$ structure; b) $n-i-p$ structure.

Basically, sputtered indium tin oxide (ITO) substrate is used as the transparent electrode, and evaporated metals (silver, gold or aluminium) are utilized as the opaque electrodes. As shown in Figure 3.1, there are two architectures for perovskite LEDs, distinguished by the electronic property of substrate to deposit perovskites, namely, $p-i-n$ and $n-i-p$ structures. The electrons and holes are injected from the EIL and HIL to the emissive layer, respectively. The EIL and HIL used here facilitate the charge injection and the same time, form an energy confinement structure for the injected charge carriers. Emission is generated when the electrons and holes meet with each other and recombine radiatively in the emissive layer. 


\section{Perovskite LEDs}

The EIL and HIL play important roles not only on perovskite film growth and the resulting film quality, but also on charge injection and balanced transport within in the devices. These commonly used interfacial materials in perovskite LEDs can be categorized into p-type and n-type (Table 3.1), which facilitate the injection of holes and electrons, respectively.

Table. 3.1 Summary of commonly used p-type and n-type interfacial layer materials in perovskite LEDs.

\begin{tabular}{cc}
\hline p-type (HIL) & n-type (EIL) \\
\hline Poly(3,4-ethylenedioxythiophene) & $\begin{array}{c}2,2^{\prime}, 2 \text {-'-(1,3,5-Benzinetriyl)-tris(1- } \\
\text { phenyl-1-H-benzimidazole) (TPBi) }\end{array}$ \\
polystyrene sulfonate (PEDOT:PSS) & \\
Poly[N,N'-bis(4-butylphenyl)-N,N' \\
bis(phenyl) -benzidine (Poly-TPD) \\
Poly(9-vinylcarbazole) (PVK) \\
Zoly[(9,9-dioctylfluorenyl-2,7-diyl)- \\
co-(4,4'-(N-(4-sec-butylphenyl) \\
diphenylamine)) (TFB), \\
4,4'-bis(N-carbazolyl)-1,1'-biphenyl \\
(CBP) \\
Nickel oxide (NiO $)$ \\
\end{tabular}

\subsection{Working mechanism of perovskite LEDs}

In a typical perovskite LED, the light generating process can be simply described as below:

1. Charge injection from the electrode to the EIL (or HIL);

2. Electrons (or holes) transport within the EIL (or HIL);

3. Electrons (or holes) injection from EIL (or HIL) to the light-emitting layer;

4. Electrons and holes meet with each other and recombine within the emissive layer radiatively or non-radiatively. In different perovskite $3 \mathrm{D}, 2 \mathrm{D}$ or $0 \mathrm{D}$ perovskites) emission layer, the radiative recombination can be accomplished by band-to-band free carrier recombination or forming excitons.

5. The generated light emission escapes from the emission layer to outside of the device stacks. 


\section{Perovskite LEDs}

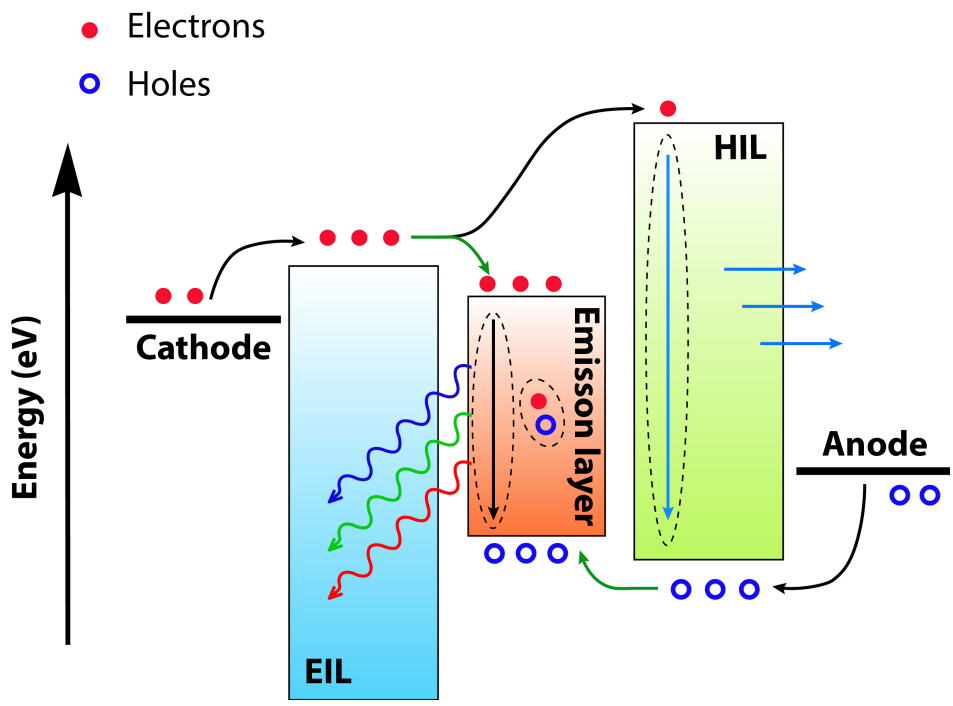

Figure 3.2 Typical energy level alignment of a perovskite LED.

These five steps determine the final device efficiency of perovskite LEDs. The light emission spectra are determined by the bandgap $\left(E_{g}\right)$ of the emissive layer. In order to confine the injected charge carriers within the perovskite emission layer to achieve high EL performance, it is of critical importance to properly choose charge injection layers with suitable energy levels (shown in Figure 3.2). This energy confinement structure ensures that electrons injected from the CB of ETL face a high energy barrier to jump over to the CB of HTL, vice versa for holes. In this case, all the injected charge carriers are confined within the perovskite emission layer, promoting a high charge carrier density for efficient radiative recombination.

\subsection{Performance parameters of perovskite LEDs}

The performance of perovskite LEDs is evaluated by measuring the intensity of EL emission spectra and the electrical power it consumes. The intensity of the light emission can be studied by radiant flux $\left(\Phi_{\mathrm{e}}, \mathrm{W}\right)$ or brightness (also known as Luminance, $\mathrm{cd} \mathrm{m}^{-2}$ ) via integrating the light emission spectrum. For light emission in the visible region (400$700 \mathrm{~nm}$ ), brightness is a frequently used parameter to quantify the performance of LEDs since it incorporates human version ability towards the emission light.

We summarize the key parameters to evaluate the device performance of a LED in Table 3.2. The driving voltage is defined as turn on voltage $\left(V_{\text {turn-on }}\right)$ when the brightness of device reaches $1 \mathrm{~cd} \mathrm{~m}^{-2}$. The $V_{\text {turn-on }}$ of a device also reflects whether a barrier free 


\section{Perovskite LEDs}

charge injection can be achieved or not. While for LEDs emitting in infrared region, radiance $\left(\mathrm{W} \mathrm{sr}^{-1} \mathrm{~m}^{-2}\right)$ is a primary parameter to characterize the emitted light intensity.

Power efficiency $\left(\mathrm{lm} \mathrm{W}^{-1}\right)$, current efficiency $\left(\mathrm{cd} \mathrm{A}^{-1}\right)$ and EQE $(\%)$ are three main parameters that used to evaluate how efficiently an LED works. Since the EQE value is independent on the emission wavelength, it is an important parameter for the performance comparison between LEDs with different emission colors. The EQE is defined as the ratio between the number of photons $\left(\mathrm{N}_{\text {photon }}(\mathrm{V})\right)$ emitted outside of the device by the LED and the number of charge carriers $\left(\mathrm{N}_{\text {charges }(\mathrm{V})}\right)$ injected into the device at a certain bias (V).

Table 3.2 Summary of important parameters for LEDs performance.

\begin{tabular}{|c|c|}
\hline Item & Unit \\
\hline $\mathrm{V}_{\text {turn-on }}$ & $\mathbf{V}$ \\
\hline Luminance & cd m $\mathbf{m}^{-2}$ \\
\hline Radiance & $\mathrm{W} \mathbf{s r}^{-1} \mathbf{m}^{-2}$ \\
\hline EQE & $\%$ \\
\hline Power efficiency & $\operatorname{lm~} \mathbf{W}^{-1}$ \\
\hline Energy conversion efficiency & $\%$ \\
\hline Current efficiency & 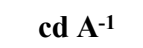 \\
\hline
\end{tabular}

The EQE of a device is critically dependent on the charge injection efficiency $\left(\eta_{i n j}\right)$, charge radiative recombination efficiency $\left(\eta_{r a d}\right)$ and light out-coupling efficiency $\left(\eta_{\text {out }}\right.$ coupling), as described as below,

$$
E Q E=\eta_{\text {inj }} \cdot \eta_{\text {rad }} \cdot \eta_{\text {out-coupling }}
$$

Efficient charge injection is a perquisite to achieving a high-efficiency LEDs. Poor and unbalanced mobilities of the charge injection layers, mismatch of energy levels between charge injection layers and light-emitting layers all result in decreased $\eta_{i n j}$, which deteriorates the overall device performance. In addition, defects or traps states within the charge injection layer also decrease the $\eta_{i n j}$. After charge injection, electrons and holes arriving in the light-emitting layer recombine either radiatively or non-radiatively. Only the radiative recombination contributes to the light emission. $\eta_{\text {inj }}$ and $\eta_{\text {rad }}$ determine the internal quantum efficiency (IQE) of an LED, which can be expressed as,

$$
I Q E=\eta_{\text {inj }} \cdot \eta_{\text {rad }}
$$


By excluding the $\eta_{\text {out-coupling }}$ of the devices, the IQE values is used to determine the efficiency of the radiative recombination within the emission layer. IQE values are highly related with PLQE of the light-emitting layer.

Finally, $\eta_{\text {out-coupling }}$ is another important parameter to be considered when studying the device performance. As shown in Figure 3.3, due to the different light refractive indices (n) of glass substrate, ITO, charge injection and light emitting layers and air, the fraction of light extracted from the device is commonly below $\sim 25 \%$ of the total internal emission. In the case of perovskite LEDs, optical simulation results show that the maximum EQEs of 3D and 2D perovskite LEDs on planar substrates can reach around $25 \%$ and $20 \%$ respectively. ${ }^{[73]}$

Since most of the light loss is caused by the substrate waveguide model, creating certain structures on the substrates is an effective way to increase the $\eta_{\text {out-coupling. }}$. These methods include fabricating micro-lenses on top of the substrates surface, preparing micro-cavity by depositing dielectric distributed Bragg reflector (DBR) and depositing nanopatterned or nano-porous structured functional layer in the device. ${ }^{[74-77]}$

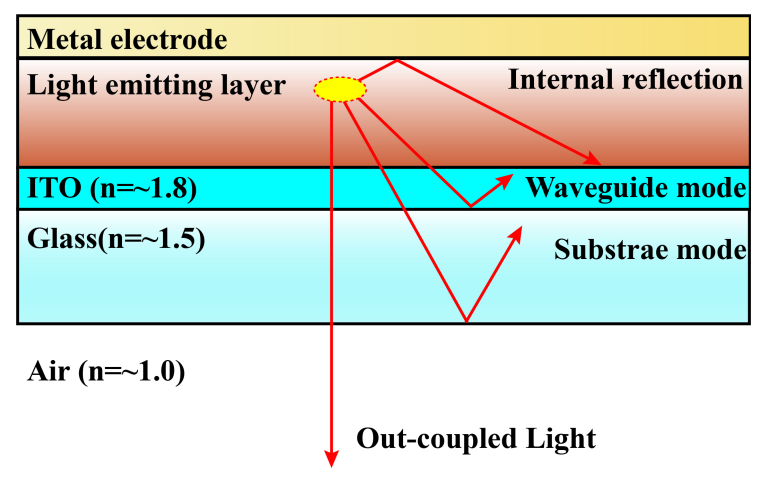

Figure 3.3 Brief diagram of light outcoupling from a planar structured LED fabricated on ITO substrates.

\subsection{Reliable measurements of perovskite LEDs}

The performance of the perovskite LEDs studied in this thesis are all measured by a homemade LED testing platform in a $\mathrm{N}_{2}$ filled glovebox at room temperature (shown in Figure 3.4). A complete perovskite LED is placed on top of an integrating sphere with the emission side towards the input. The working area of device is placed at the centre of the light collecting hole. The integrating sphere together with a $1000 \mu \mathrm{m}$ optical fiber is used to collect the light emission data from the device, while a Keithley 2400 is used 


\section{Perovskite LEDs}

to drive the device and collect the electrical signal. The device emission spectrum is detected by a spectrometer (in our case, an ocean optics QE Pro spectrometer is used). ${ }^{[2}$, 78]

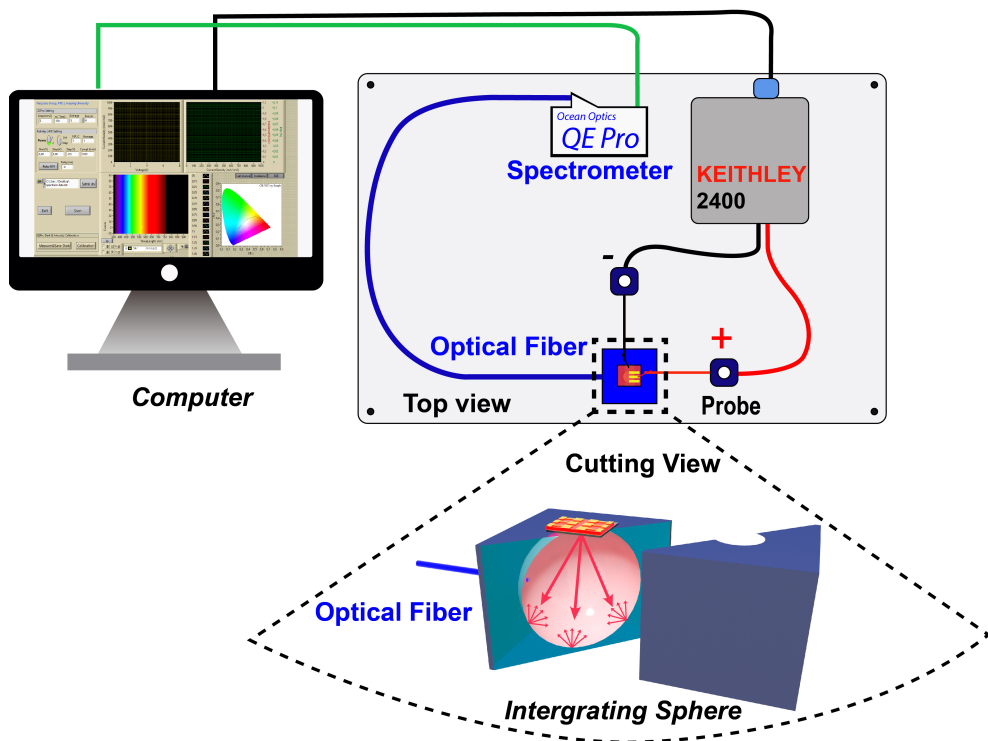

Figure 3.4 Detailed layout of LEDs performance measurement setup.

By collecting the light emission of an LED at different current densities (or biases), one can obtain a curve of radiance or brightness as a function of current density ( $R \& J$ or $L$ $\& J)$, which is important to study the performance of an LED. The collected emission data (emission spectrum $\mathrm{S}_{\lambda}$, Unit: counts) and electrical data (voltage $(V)$, current density $(J)$ ) will be processed in a computer to calculate the EQE, brightness and radiance values etc. of the working device at different driving current densities. Before measuring the LEDs, the LED testing platform is calibrated by a visible-NIR (Vis-NIR) radiometric calibration source for the absolute light intensity accuracy and a HG-1 light source for the calibration of the wavelength accuracy. After that, a calibration curve $\mathrm{C}_{\lambda}$ $\left(\mu \mathrm{W}\right.$ s Count $\left.{ }^{-1}\right)$ ) compared to the light spectrum of standard Vis-NIR radiometric calibration source is obtained. The spectrometer integrating time is set as $t(\mathrm{~s})$ and the dark spectrum $D_{\lambda}$ (Unit: counts) is collected right before each measurement.

According to the parameters obtained from the spectra, the spectral flux $\left(\Phi_{\lambda}, \mu \mathrm{W} \mathrm{nm}{ }^{-1}\right)$ is calculated as, 


$$
\Phi_{\lambda}=\frac{\left(S_{\lambda}-D_{\lambda}\right) \cdot C_{\lambda}}{\Delta \lambda \cdot t}
$$

The number of photons $\left(N_{\text {photon }}(V)\right)$ generated can be calculated as,

$$
N_{\text {photon }(V)}=\int \Phi_{\lambda} \cdot t \cdot \frac{\lambda}{h c} d \lambda
$$

where $h$ is the plank constant $\left(6.626 \times 10^{-34} \mathrm{~J} \mathrm{~s}^{-1}\right), c$ is the speed of light in vacuum $\left(3.0 \times 10^{8} \mathrm{~m} \mathrm{~s}^{-1}\right), \Delta \lambda(\mathrm{nm})$ is the step size of the spectrum, which is determined by the spectrometer.

The injected electrons $\left(\mathrm{N}_{\text {charges }}(\mathrm{V})\right)$ can be described as,

$$
N_{\text {charges }(V)}=\frac{J(V) \cdot A \cdot t}{e}
$$

where $J(V)$ (unit, $\mathrm{mA} \mathrm{cm}{ }^{-2}$ ) is the current density under a bias $V$ (unit, V). The device working area is $A\left(\mathrm{~m}^{2}\right)$. $e$ is the elementary charge $\left(1.602 \times 10^{-19} \mathrm{C}\right)$.

Then the EQE can be calculated as.

$$
E Q E(V)=\frac{N_{\text {photon }(V)}}{N_{\text {charges }(V)}} \times 100 \%=\int \frac{\Phi_{\lambda} \cdot \lambda \cdot e}{h c \cdot J(V) \cdot A} \cdot d \lambda \cdot 100 \%
$$

For the characterization of light emission in visible range, we could obtain the luminous flux ( $\Phi_{v}$, unit: $1 \mathrm{~m}$ ), according to the EL spectrum, which is described as below,

$$
\Phi_{v}=\frac{683}{1000000} \cdot \int_{380}^{780} \Phi_{\lambda} \cdot d \lambda \cdot V_{\lambda}
$$

where $V_{\lambda}$ is human version function.

Therefore, Luminance $\left(L_{v}\right.$, unit: $\left.\mathrm{cd} \mathrm{m}^{-2}\right)$ is described as,

$$
L_{v}=\frac{\Phi_{v}}{A \cdot \pi}
$$

Radiance $\left(R\right.$, unit: $\left.\left.\mathrm{W} \mathrm{sr}^{-1} \mathrm{~m}^{-2}\right)\right)$ is described as

$$
R=\int \frac{\Phi_{\lambda}}{A \cdot \pi} d \lambda
$$




\section{Perovskite LEDs}

With the luminance and device current density, we could obtain the current efficiceny $\left(\eta_{c u}\right.$, unit: $\left.\mathrm{cd} \mathrm{A}^{-1}\right)$, which is decribed below,

$$
\eta_{c u}=\frac{L_{v}}{J(V)}
$$

$\eta_{c u}$ is another important parameter to describe the efficiency of a visible LED.

The power efficiency ( $\eta_{\text {power }}$, unit: $1 \mathrm{~m} \mathrm{~W}^{-1}$ ) can be calculated as fllowing,

$$
\eta_{\text {power }}=\frac{\Phi_{v}}{J(V) \cdot V \cdot A}
$$

\subsection{Fabrication procedures of perovskite LEDs}

The fabrication process of a perovskite LED in this thesis can be separated into the following steps:

1. Substrates cleaning. All the purchased ITO substrates are soaked in detergent solution for $24 \mathrm{~h}$ before use. The detergent solution dissolves the oil and chemical residues on the ITO surface, ensuring a clear surface for device fabrication. After that all the substrates are washed with deionized water five times to fully remove detergent before drying with a high-flow $\mathrm{N}_{2}$. The substrates are then treated with ultraviolet ozone for $10 \mathrm{~min}$, further removing the residual containments on the ITO surface.

2. EIL deposition. $\mathrm{ZnO}$ nanoparticles ( $\mathrm{ZnO} \mathrm{NPs}$ ) dispersed in ethanol were used for the deposition of EIL. The ZnO NPs solution is prepared by a solution precipitation process as described in literature. ${ }^{[78,79]}$ Typically, zinc acetate hydrate $\left(\mathrm{Zn}(\mathrm{Ac})_{2} \cdot 2 \mathrm{H}_{2} \mathrm{O}\right)$ solution in DMSO $(15 \mathrm{~mL}, 0.1 \mathrm{M})$ is heated and stirred at $30{ }^{\circ} \mathrm{C}$ for $15 \mathrm{~min}$ to fully dissolve $\mathrm{Zn}(\mathrm{Ac})_{2} \cdot 2 \mathrm{H}_{2} \mathrm{O}$. Then $5 \mathrm{~mL}$ tetramethylammonium hydroxide pentahydrate $\left(\mathrm{TMAH} \cdot 5 \mathrm{H}_{2} \mathrm{O}\right)$ in ethanol $(0.56 \mathrm{M})$ is added in the $\mathrm{Zn}(\mathrm{Ac})_{2} \cdot 2 \mathrm{H}_{2} \mathrm{O}$ solution. The mixture solution is stirred for another $24 \mathrm{~h}$ before the precipitation process. After that, $45 \mathrm{~mL}$ ethyl acetate is added into the solution to precipitate ZnO NPs. The resulting ZnO NPs are dissolved in $2 \mathrm{~mL}$ ethanol and washed with ethyl acetate for one more time. Finally, the obtained $\mathrm{ZnO}$ NPs are dispersed in ethanol and filtered with a 0.45 $\mu \mathrm{m}$ PTFE filter.

$\mathrm{ZnO}$ NPs solution is spin-coated at 4000 r.p.m. before transporting into the glovebox. We use a further diluted PEIE solution (0.05 wt \%) to modify the surface of $\mathrm{ZnO}$. The PEIE solution is spin-coated at 5000 r.p.m and annealed 


\section{Perovskite LEDs}

at $100{ }^{\circ} \mathrm{C}$ for $10 \mathrm{~min}$ consequently. While for devices on $\mathrm{SnO}_{2}$ and $\mathrm{TiO}_{\mathrm{x}}$, the precursor solutions are prepared as described in literature and deposited at 5000 r.p.m and annealed at $100{ }^{\circ} \mathrm{C} .{ }^{[80,81]}$

3. Perovskite film deposition. Perovskite precursor solutions are prepared by dissolving $\mathrm{PbX}_{2}, \mathrm{AX}$ and additives in anhydrous DMF with different concentrations. The solutions are heated at $60^{\circ} \mathrm{C}$ for $2 \mathrm{~h}$ to ensure that all the salts are fully dissolved. All the perovskite films are prepared by spin-coating the precursor solutions at 4000 r.p.m, followed by annealing the films at 100 ${ }^{\circ} \mathrm{C}$ for $10 \mathrm{~min}$ in a $\mathrm{N}_{2}$ filled glovebox.

4. HIL preparation. We use TFB as HIL in the LEDs. TFB is prepared by spincoating the solution (12 mg mL-1 in chlorobenzene (CB)) at 3000 r.p.m. After that the substrates are transferred into the thermal evaporator for electrode deposition.

5. Electrode deposition. All the substrates are placed on a shadow mask for function layer (molybdenum trioxide $\left(\mathrm{MoO}_{3}\right)$ ) and opaque electrodes deposition. The electrode materials used in this thesis are silver $(\mathrm{Ag})$ and gold $\mathrm{Au}$ ). The pressure of the evaporation chamber needs to be pumped to $2 \times 10^{-6}$ mbar before materials deposition. The working area of our devices in this thesis is $7.25 \mathrm{~mm}^{2}$.

\subsection{Characterizations of perovksite films}

\subsubsection{Time-correlated single-photon counting}

Time-correlated single-photon counting (TCSPC) is a widely used technique to study the charge carrier dynamics of semiconductors. A brief diagram of TCSPC is shown in Figure 3.5. The laser generates periodic excitation with very short pulses (the laser pulse lasts for 5 to $10 \mathrm{ps}$ with a high frequency) that go through a beam splitter, resulting in two identical laser beams. One of the beams excites the sample surface and generates fluorescence photons, which are detected by photodiode 1 (PD 1). The other one is used to synchronize the time domains, which will be detected by photodiode 2 (PD 2). The timing electronics records the arriving time of fluorescence photons after the laser excitation every single time. By accumulating the excitation arriving times for many cycles, TCSPC system acquires a histogram figure of photon arriving times. 


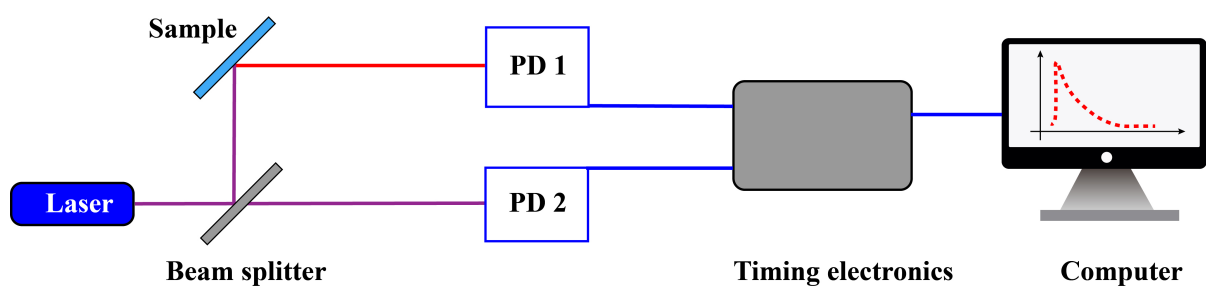

Figure 3.5 Brief diagram of the TCSPC setup.

In this thesis, we obtain the TCSPC decay curves using an Edinburgh Instruments spectrometer (FLS980) with pulsed lasers (less than $100 \mathrm{ps}, 0,1 \mathrm{MHz}$, YSL Supercontinuum Source SC-PRO).

The obtained PL decay curves are fitted by a bi-exponential equation:

$$
I_{(t)}=I_{\left(t_{0}\right)}+A_{1} e^{-\frac{t}{\tau_{1}}}+A_{2} e^{-\frac{t}{\tau_{2}}}
$$

where $A_{1}, A_{2}$ are amplitudes of the lifetime components and $\tau_{1}, \tau_{2}$ are the lifetime of the fast and slow recombination, respectively.

The average PL lifetime ( $\left.\tau_{\text {average }}\right)$ is calculated by

$$
\tau_{\text {average }}=\frac{A_{1} \times \tau_{1}+A_{2} \times \tau_{2}}{A_{1}+A_{2}}
$$

Light-intensity-dependent TCSPC is achieved by changing the laser intensity with an attenuator and collecting TCSPC information at different excitation intensities. The laser intensities are recorded by a photodiode.

\subsubsection{Photoluminescence quantum efficiency}

The photoluminescence quantum efficiency (PLQE) value is a very important parameter to study the radiative recombination in optoelectronic materials. Measuring correct PLQE values of solid films is of great importance. Since light-emitting layers are solidstate films, the waveguiding phenomena and angular dependence of the light emission from the solid sample make the PLQE measurement complex. In order to avoid these influences, an integrating sphere coated with diffusing white reflective material, is often used to collect the excitation and light emission intensity. The spectrometer and integrating sphere are connected by an optical fiber. The spectrometer-fiber-integrating sphere system is further calibrated by a standard light source (tungsten lamp) for accurate light intensity detection. ${ }^{[82]}$ 


\section{Perovskite LEDs}

In this thesis, the PLQE results of perovskite films are obtained by an integrated system composed of a $450 \mathrm{~nm}$ continuous wavelength laser, an optical fiber, a spectrometer and an integrating sphere. The laser is directed into the integrating sphere through a small entrance slit, and the spectra are collected by a CCD spectrometer (Ocean Optics). Detailed measurement process is displayed in Figure 3.6 below. ${ }^{[83]}$

The measurement consists of three steps,

1) Before mounting the film sample, the light intensity ( $\left.L_{\text {blank }}\right)$ of the laser is collected.

2) Mount the film sample on the holder, ensure that the laser illuminate through the sample, and obtain PL emission intensity $\left(E_{\mathrm{On}}\right)$ and laser intensity $\left(L_{\mathrm{On}}\right)$.

3) Tune the laser angle slightly so that the laser strikes on the wall of the integrating sphere directly, and obtain laser intensity $L_{\text {off }}$ and emission intensity intensity $E_{\text {Off. }}$
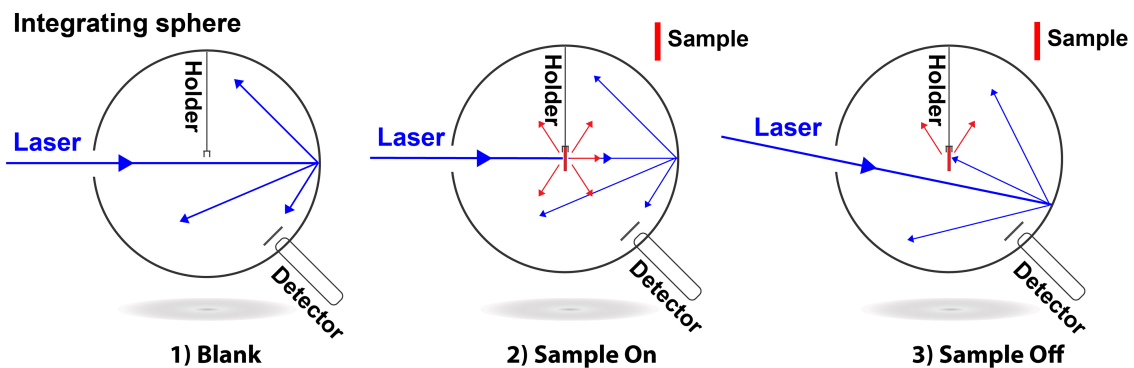

Figure 3.6 Brief diagram of the PLQE measurement.

The absorbance $(\alpha)$ of the film sample can be expressed as,

$$
\alpha=\left(1-\frac{L_{O f f}}{L_{O n}}\right)
$$

The PLQEs can be calculated as,

$$
P L Q E=\frac{\text { Emitted phonons }}{\text { absorbed photons }}=\frac{E_{\text {On }}-(1-\alpha) \cdot E_{\text {off }}}{L_{\text {Blank }} \cdot \alpha}
$$

Light-intensity-dependent PLQEs are obtained by changing the light intensity of the incident laser via an attenuator, and PLQE values at different excitation intensities are then collected 


\section{Perovskite LEDs}

\subsubsection{In-situ PL spectroscopy}

The film formation process plays an important role on the resulting film properties of the perovskite light-emitting layer. In-situ PL spectroscopy is a fast and convenient way to study the film formation process. The in-situ PL spectra of perovskite films during the film formation are acquired by a homemade spectrometer setup (Ocean optics QE Pro), of which the layout is shown in Figure 3.7. The perovskite films are placed on a pre-heated hot plate set at a certain temperature right after starting to collect the spectra. The perovskite films are excited with a pulsed $450 \mathrm{~nm}$ or $530 \mathrm{~nm}$ laser, which gives a pulse with 0.1-5 s duration and 1-60 s intervals. In order to avoid the influence of the laser on light detection, a long-pass optical filter is placed between the sample and the optical fiber input entrance.

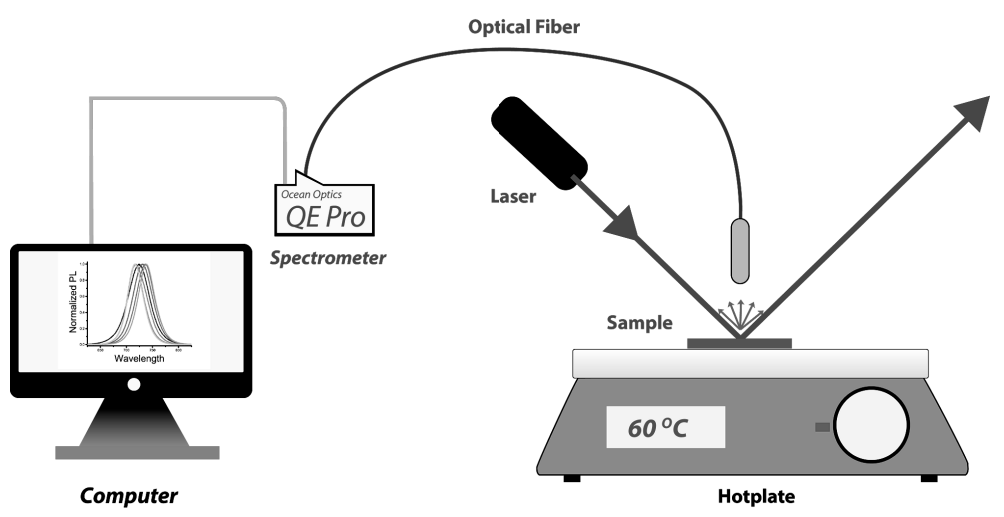

Figure 3.7 Brief diagram of in-situ PL measurement setup.

\subsubsection{Fourier transform infrared spectroscopy}

Fourier transform infrared (FTIR) spectroscopy is a commonly used technique to study the structure properties and components of organic or hybrid materials by collecting infrared absorption or transmission spectra over a wide region (typically, $400 \mathrm{~cm}^{-1}$ to $4000 \mathrm{~cm}^{-1}$ ). The low photon energies of the infrared light, which are not enough to excite the electrons, can be absorbed by covalent bonds in the sample, inducing bonds vibration. After going through the sample, the transmitted light is collected by an infrared (IR) detector. By calculating the percentage of light absorbed by the sample, we can obtain a FTIR absorption or transmission spectrum. Since different material structures selectively absorb light radiations in different wavelengths, the obtained FTIR spectrum is a 'fingerprint' of the material. Therefore, FTIR spectroscopy is often used to obtain 


\section{Perovskite LEDs}

structural and compositional information of the samples through analyzing the spectra peaks position and intensity of specific functional groups and chemical bonds.

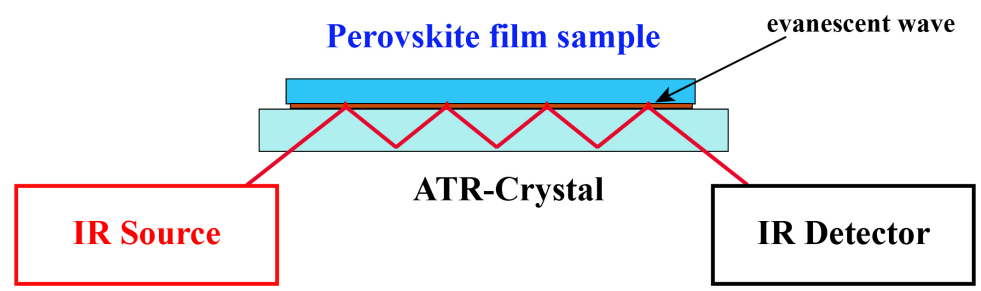

Figure 3.8 Schematic diagram of an ATR-FTIR system.

In our study, perovskite films are deposited on ITO substrates. A technique named attenuated total reflectance (ATR) is used in order to detect the solid samples on substrates directly. We show a brief diagram of an ATR-FTIR characterization system in Figure 3.8. Light generated from the IR source is incident into the ATR-crystal in a certain angle. Due to the large refractive index of the ATR-crystal, the incident IR light undergoes total internal reflections several times within the ATR-crystal. At the interface between film samples and ATR-crystal, the total internal reflections generate evanescent wave that penetrates into the film samples. ${ }^{[84]}$ The penetrating depth $(D p)$ of evanescent wave from the surface of ATR-crystal is described as below,

$$
D p=\frac{\lambda \times n_{1}}{2 \pi \sqrt{\sin \theta^{2}-\left(\frac{n_{2}}{n_{1}}\right)^{2}}}
$$

where $n_{1}$ and $n_{2}$ are the refractive index of the ATR-crystal and sample, respectively. $\theta$ is the incident angle of IR light. $\lambda$ is the wavelength the incident IR light.

The penetrated IR light from the ATR-crystal can be absorbed by the sample on top. By collecting the IR light changes after several internal reflections, a FTIR spectrum is obtained. Since the intensity of evanescent wave decreases exponentially with increasing distance from the surface of the ATR-crystal, a force is commonly added on the samples to ensure a close contact between the sample and ATR-crystal.

In this thesis, all the ATR-FTIR spectra are collected from a PIKE MIRacle ATR accessory that is integrated in a Vertex 70 Spectrometer (Bruker). A diamond prim is used as the ATR crystal. A DLaTGS detector is used to detect the intensity of IR light at room temperature. The spectra are acquired with 30 scans between 400 and $4000 \mathrm{~cm}^{-}$ 1. For the characterization of perovskite films on different substrates, background spectra are firstly collected by measuring the perovskite film substrates. 


\section{Perovskite LEDs}

\subsubsection{X-ray diffractometry}

X-ray diffractometry (XRD) is a widely used technique to study the material crystallinity. Basically, the X-ray is generated from electron impact on metal surface. When the excited electrons return to the core level of the metal atoms, a characteristic $\mathrm{X}$-ray is emitted from the metal surface. In our setup, copper $(\mathrm{Cu})$ is used as the target metal and the wavelength of the generated X-ray $\left(\lambda_{K \alpha}\right)$ is $0.154 \mathrm{~nm}$.

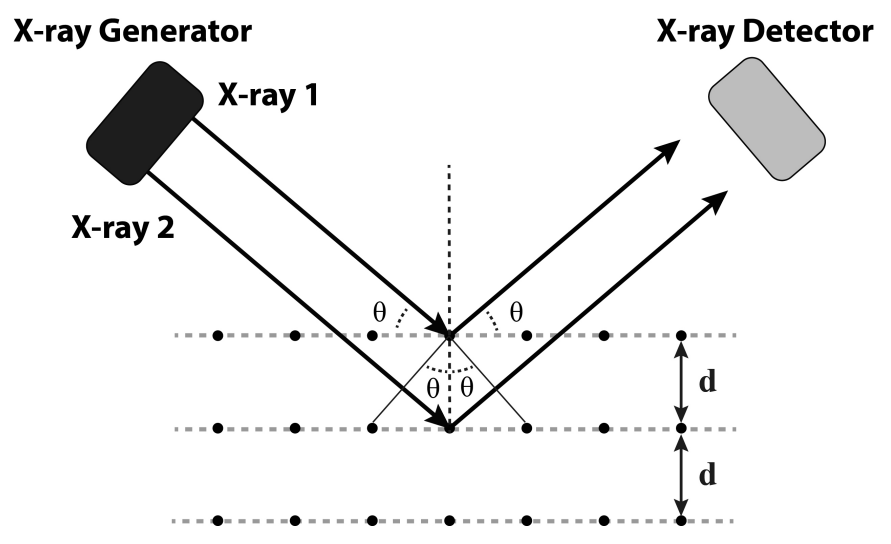

Figure 3.9 Schematic diagram of XRD measurement.

The diffraction patterns obtained with X-ray irradiation reflects the crystalline information of the sample. As shown in Figure 3.9, when the X-ray (X-ray 1 and X-ray 2 in the diagram) with the same wavelength and phase information is incident on a crystalline sample, it shows light interference phenomenon due to the periodic atoms in the crystallized sample. Only constructive interference will generate an enhanced signal in the X-ray detector. The relation between incident angle $(\Theta)$, X-ray wavelength $(\lambda)$ and plane distance (d) can be described as following,

$$
n \lambda=2 \cdot d \cdot \sin \theta
$$

According to the equation, highly crystalized sample generates diffraction peaks with high intensity and narrow full width at half maximum (FWHM), since less scattering of the X-ray and high order in the sample. The information of the peak widening is also used to estimate the crystal sizes within the sample. P. Scherrer found the relation between peak widening and crystal sizes, which is described as 'Scherrer equation' [85] and shown below,

$$
L=\frac{K \cdot \lambda}{B \cdot \cos \theta}
$$




\section{Perovskite LEDs}

where $\mathrm{K}$ is the shape factor ( 0.94 for spherical crystals with cubic symmetry), $\lambda$ is the incident X-ray wavelength $(\lambda=0.154 \mathrm{~nm})$. B is the integral peak width (in radians $2 \theta$ ), which is also the FWHM of the peak and $L(\mathrm{~nm})$ is the estimated crystal sizes. However, when calculating the crystal sizes, the influence of instrument, lattice strain should be considered since they also effect the widening of diffraction peaks.

\subsubsection{Scanning electron microscopy}

Scanning electron microscopy (SEM) is a widely used technique to detect the microstructure, composition and morphology of the sample. Among all the functions of SEM, the commonly used ones are secondary electron imaging (SEI) and Energydispersive X-ray (EDX) spectroscopy. The former model produces a high-resolution image of sample morphology, while the latter helps analyze sample compositions and elements.

a)

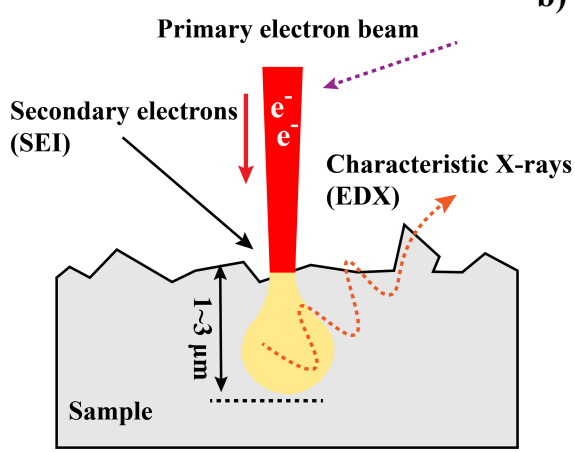

b)

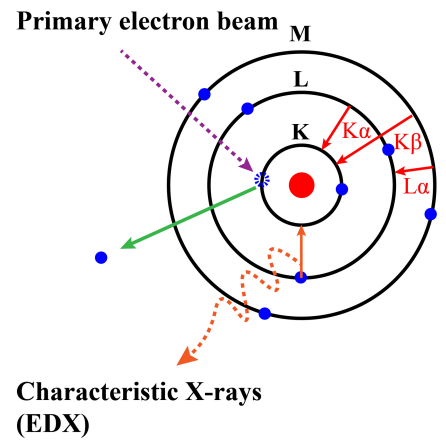

Figure 3.10 a) Brief diagram of SEM imaging and EDX; b) mechanism of characteristic X-ray generation after electron excitation.

A brief diagram of the SEI mechanism is shown in Figure 3.10a. A sample is mounted on top of the stage inside of a chamber. The incident electron beam is accelerated by a bias (in our case $5 \mathrm{kV}$ ) and then hits on the surface of the sample. Due to the continues scattering of the electrons (by sample atoms), the incident electron beam works in a 'pear' shape cross-section within the sample. The penetration depth of the incident electron beam reaches around 1 to $3 \mu \mathrm{m}$. The high-energy electrons interact with the sample materials, generating secondary electrons with much lower energy. Since only the secondary electrons generated near the surface of sample can be collected by the detector and the sample morphology influence dramatically on the electron intensity, these secondary electrons are used to produce the image of the sample morphology. 


\section{Perovskite LEDs}

While for the EDX measurement, the primary electron beam can excite the electron from the inner shell of atoms, e.g. from $\mathrm{K}$ shell to $\mathrm{L}$ shell of the sample. Then the electron at a higher energy level tends to decay to the electron vacancy at the low-level shell, at the same time, generating a characteristic X-ray signal, as shown in Figure 3.10b. Different elements possess different energy level structures, making the characteristic $\mathrm{X}$-ray useful for the analysis of elements and compositions in the sample. In addition, combining EDX model with the scanning electron beams, one can easily obtain distributions of different elements within a sample, known as EDX mapping. 


\section{Chapter 4}

\section{Defects passivation of perovskites}

\subsection{Defects in perovskites}

Defects in the light-emitting layer have important influence on the charge carrier recombination dynamics. In order to enhance the efficiency of perovskite LEDs, it is necessary to minimise trap states. As mentioned before, the unique defects-tolerance property ensures that perovskites feature low level trap-assisted recombination, compared with traditional inorganic materials. ${ }^{[86]}$ However, solution processed perovskite films contain a large number of defects at crystal or domain surfaces, which deteriorates the performance and stability of perovskite LEDs. ${ }^{[87,88]}$ In this chapter, we will discuss the defects in perovskites, charge carrier recombination mechanism and summarize efficient strategies on mediating these defects.

In the conventional inorganic semiconductors, imperfect crystal growth leads to the formation of various defects, including atoms vacancies, interstitials, antisite substitutions and edge dislocations of crystals etc. In addition, impurities from the source materials or film deposition environment also result in defects. ${ }^{[89]}$ These crystal defects generate deep traps for charge carriers, which is detrimental to the electronic and optical properties of semiconductors. ${ }^{[89]}$ When it comes to perovskites, the defects formed during the crystal growth are various. Here we use $3 \mathrm{D} \mathrm{MAPbX}_{3}$ perovskite as an example and summarize various defects of $\mathrm{MAPbX}_{3}$ with three different kinds in Table 4.1. According to the table, vacancy defects in perovskites contain MA vacancy $\left(\mathrm{V}_{\mathrm{MA}}\right), \mathrm{Pb}$ vacancy $\left(\mathrm{V}_{\mathrm{Pb}}\right)$ and halides vacancy $\left(\mathrm{V}_{\mathrm{X}}\right)$. Another type of defects is interstitial, which are interstitials of $\mathrm{MA}\left(\mathrm{MA}_{\mathrm{i}}\right), \mathrm{Pb}\left(\mathrm{Pb}_{\mathrm{i}}\right)$ and halides $\left(\mathrm{X}_{\mathrm{i}}\right)$. In addition, Antisite substitutions generate different defects, namely, $\mathrm{MA}$ on $\mathrm{Pb}(\mathrm{MAPb}), \mathrm{MA}$ on halides $\left(\mathrm{MA}_{\mathrm{x}}\right), \mathrm{Pb}$ on MA (PbMA), $\mathrm{Pb}$ on halides $(\mathrm{Pbx})$, halides on MA $\left(\mathrm{X}_{\mathrm{MA}}\right)$ and halides on $\mathrm{Pb}$ $(\mathrm{XPb})$.

Table 4.1 Summary of defects in perovskites. 


\section{Defects in $\mathrm{MAPbX}_{3}$}

\begin{tabular}{cc}
\hline Vacancies & $\mathrm{V}_{\mathrm{A}}, \mathrm{V}_{\mathrm{Pb}}$, and $\mathrm{V}_{\mathrm{x}}$ \\
Interstitials & $\mathrm{A}_{\mathrm{i}}, \mathrm{Pb}_{\mathrm{i}}$, and $\mathrm{X}_{\mathrm{i}} ;$ \\
Antisite substitutions & $\mathrm{A}_{\mathrm{Pb}}, \mathrm{A}_{\mathrm{X}}, \mathrm{Pb}_{\mathrm{A}}, \mathrm{Pb}_{\mathrm{X}}, \mathrm{X}_{\mathrm{A}}, \mathrm{X}_{\mathrm{Pb}}$ \\
\hline
\end{tabular}

Typical defects in perovskites are also demonstrated in Figure. 4.1. According to the density functional theory (DFT) calculations, deep energy level defects includes $\mathrm{A}_{\mathrm{Pb}}$, $\mathrm{Pb}_{\mathrm{A}}, \mathrm{Pb}_{\mathrm{x}}, \mathrm{X}_{\mathrm{Pb}}$ and $\mathrm{V}_{\mathrm{x}}$ and these defects generate deep traps in perovskites, harming the optoelectronic properties. ${ }^{[87,90]}$ On the contrary, the shallow defects only generate low energy level traps close to the $\mathrm{CB}$ or VB, showing limited influence on the emission property of perovskite films. Previous calculation results show that deep energy level defects need high formation energy, while the low energy level defects have much lower formation energy. ${ }^{[0-92]}$ Consequently, there are very limited numbers of deep trap states that affect radiative recombination process. This is also the reason for a high defectstolerance of perovskites. ${ }^{\left[93,{ }^{94}\right]}$ However, proper control on the film growth, which influences the formation energy of the defects, is still necessary. ${ }^{[90]}$

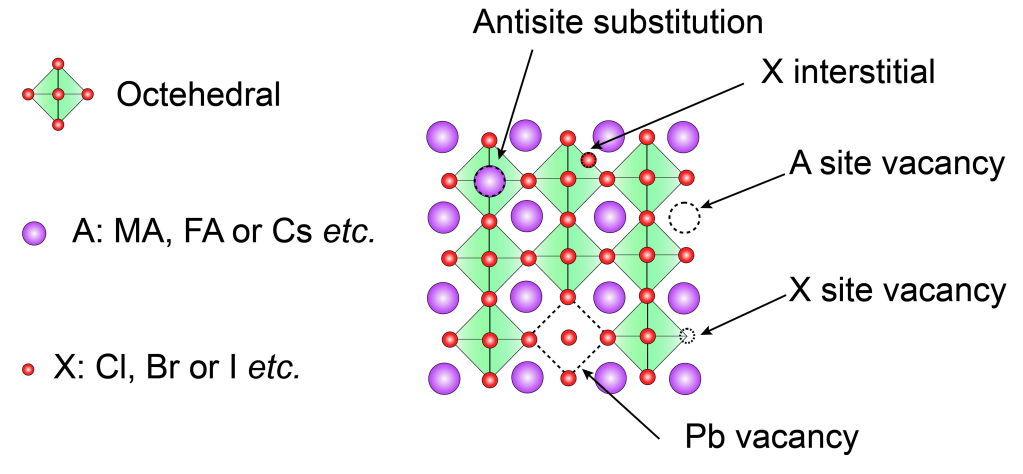

Figure 4.1 Diagram of typical defects in perovskites.

\subsection{Charge carrier recombination dynamics in perovskites}

The charge carrier recombination process is highly related to the defect states in perovskite films. As discussed above, the binding energy ( $\left.E_{\text {binding }}\right)$ of excitons in 3D perovskites are in a range of $20-50 \mathrm{meV} .{ }^{[95,96]}$ In this case, the injected electrons and 
holes will not form tightly bonded excitons at room temperature. On the contrary, they tend to exist as free charge carriers and can easily be captured by the crystal defects or dangling bonds at grain boundaries. Here we show the recombination mechanism in Figure 4.2. Only the band to band radiative recombination contributes to the light emission of LEDs. Charge carriers captured by various trap states within the bandgap all lead to non-radiative recombination. Under high charge carrier intensities, Auger recombination dominates the non-radiative recombination and leads to poor performance of perovskite LEDs.
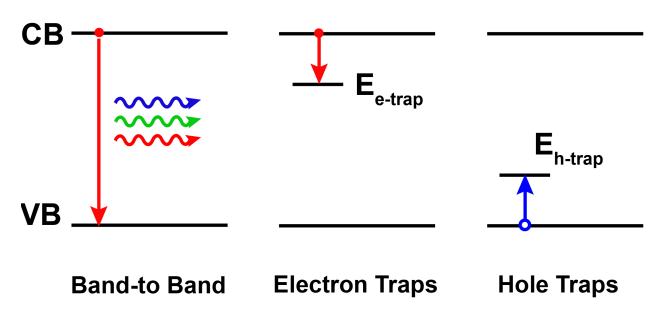

Hole Traps
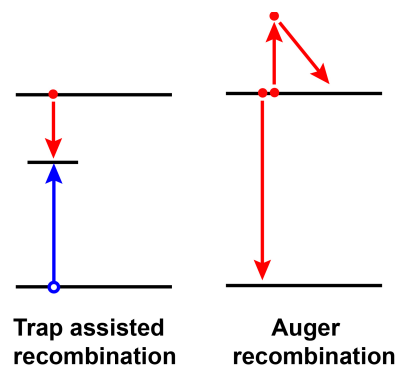

Figure 4.2 Diagram of charge recombination mechanism in perovskite.

The recombination dynamic of perovskites can be described as the following equation,

$$
\frac{d n}{d t}=G-n R_{(n)}
$$

where $G$ is the charge carrier generation rate, $n$ is the charge carrier density generated in perovskite films, $R_{(n)}$ is the total recombination rate. ${ }^{[97,98]}$

$R_{(n)}$ here can be expressed as,

$$
R_{(n)}=k_{1}+k_{2} n+k_{1} n^{2}
$$

where $k_{1}, k_{2}$ and $k_{3}$ are the rate of monomolecular charge recombination, band-to-band bimolecular recombination and Auger recombination, respectively.

According to these two equations, we notice that the charge carrier density $(n)$ plays important roles on determining the charge carrier recombination process. At relatively low carrier densities, the injected charge carriers tend to be captured by traps and defects in the perovskite film. If the charge carriers are trapped inside of deep energy defects, they decay their energy to the perovskite lattice. For charge carriers trapped into shallow traps, they either decay or are re-excited by another photon. However, in both cases, trapped charge carriers result in decreased carrier densities, making trap assisted 
recombination dominant at low carrier densities. Increasing charge carrier density helps to fill the shallow traps, leading to more efficient bimolecular recombination. In addition, increasing carrier density also improves the wavefunction overlap between electrons and holes, enhancing the probabilities for them to meet each other. Further increasing the charge carrier density leads to Auger recombination, in which the electrons at excited state decays to the ground state by donating energy and momentum to another electron, resulting in non-radiative recombination. ${ }^{[99,100]}$ In addition, unbalanced charge injection and poor charge transport properties of light-emitting layers lead to charge carrier accumulation at the interfaces, also resulting in non-radiative recombination.

Previous reports show that the recombination rate in metal halide perovskites for monomolecular charge recombination $\left(k_{1}\right)$, band-to-band bimolecular recombination $\left(k_{2}\right)$ and Auger recombination $\left(k_{3}\right)$ are in the order of $10^{6} \mathrm{~s}^{-1}, 10^{-10} \mathrm{~cm}^{3} \mathrm{~s}^{-1}$ and $10^{-28} \mathrm{~cm}^{6} \mathrm{~s}^{-1}$, respectively. ${ }^{[98]}$ The extremely high rate of monomolecular charge recombination suggests that efficient passivation, which removes the traps, is key for achieving highly luminescent perovskite films for high performance LEDs.

\subsection{Defect passivation of perovskite films}

Passivating perovskite films is an efficient way to accomplish high performance perovskite LEDs. ${ }^{[10,101]}$ The defects locate mainly at the surface and grain boundaries in perovskite films, making the defects accessible to a range of passivation agents (Figure 4.3 a). Efficient passivation of the defects can be achieved by introducing inorganic halides and organic passivation molecules with various functional groups.

\subsubsection{Inorganic halides}

Introducing alkali metal halides (potassium or rubidium halides (KX or $\mathrm{RbX})$ ) has been demonstrated for efficient defects passivation of perovskite films. ${ }^{[102,103]}$ Due to the limit of Goldschmidt's tolerance factor, the alkali metal $\mathrm{K}$ or $\mathrm{Rb}$ atoms are too small to fit into the perovskite crystal structure. Thus, when these metal halides are introduced in the perovskite films, they tend to aggregate at the surface of perovskite crystals and grain boundaries. ${ }^{[102]}$ As shown in Figure $4.3 \mathrm{~b}$, the alkali metal halides will stay at the cation or halides vacancies, eliminating the non-radiative recombination paths and contributing to enhanced PLQEs. This inorganic passivation strategy is valuable since it only introduces cation halides with small sizes, which does not affect film charge transport properties dramatically. ${ }^{[102]}$ However, the excess amount of alkali metal halides in perovskite films leads to serious aggregation at grain boundaries, hindering 
efficient charge transport. ${ }^{[104]}$ Proper strategies on removing the excess metal halides, simultaneously preserving the passivation effects, are still necessary.

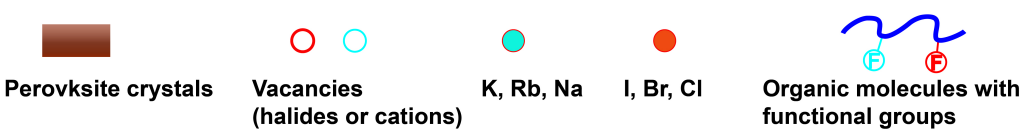

a)

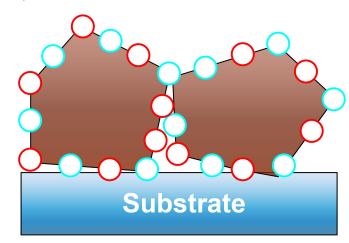

As prepared perovskite film b)

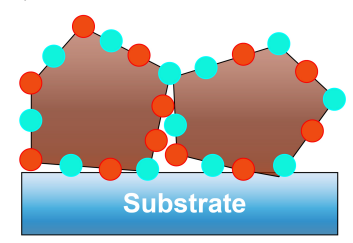

c)

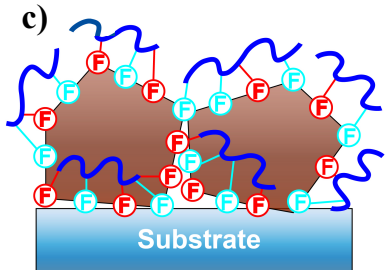

Inorganic halides passivation Organcic molecules pasivation

Figure 4.3 (a) Schematic diagram of perovskite defects; passivation of the defects through extra cation halides (b) and organic molecules (c).

\subsubsection{Organic passivation molecules.}

Organic molecules with different functional groups provide abundant choices for efficient defects passivation in perovskites. One of the advantages of organic molecules over inorganic salts is the much better solubility in the common solvents used for perovskite precursors. As a result, the uniform distribution of organic molecules offers more efficient passivating effects. Since the defects formed at perovskite crystal surface are most cation or halides vacancies, functional groups that provide extra electron pairs to un-coordinated $\mathrm{Pb}$ can heal the traps efficiently (Figure 4.3c). ${ }^{[105]}$

The first passivation example of un-coordinated $\mathrm{Pb}^{2+}$ is by treating perovskite surface with pyridine and thiophene. ${ }^{[105]}$ The $\mathrm{S}$ and $\mathrm{N}$ atoms in the molecules form coordinating bonds with $\mathrm{Pb}$, contributing to much decreased trap densities and longer carrier lifetime of perovskite films. In addition, organic molecules with amino and phosphorous group like poly-ethylenimine (PEI), ethylenediamine (EDA), trioctylphosphine oxide (TOPO) and butylphosphonic acid 4-ammonium chloride (4-ABPACl) all show efficient passivation of the defects in perovskite films, resulting in perovskite optoelectronic devices with much enhanced device performance. ${ }^{[101,106]}$ It has been also demonstrated that passivating molecules with smaller sizes can penetrate deeper inside of the perovskite domains, leading to more efficient defects passivation. ${ }^{[106]}$ 
Defects passivation of perovskites 


\section{Chapter 5}

\section{Control of the perovskite emissive layers}

The unique optoelectronic properties of metal halide perovskites, e.g. ultrahigh PLQEs, pure emission colors and excellent charge transport properties, indicate a great potential in the application of high-performance LEDs. However, precise control of the solution processing of perovskite films with high luminescence, optimal morphology and minimum defects remains big challenges for the research community. In order to obtain perovskite light-emitting films with improved morphology and optoelectronic properties, different methods have been developed. We simply divide them into the following five categories.

\subsection{Morphology control of perovskite films}

Since the first demonstration of room-temperature operated perovskite LEDs, it is believed that perovskite film morphology is an important factor that affects the device performance. ${ }^{[9]}$ In addition, 3D perovskites all show low exciton binding energy, reducing the radiative recombination rate dramatically within the emission layer. Therefore, perovskite film with a thickness of tens of nanometers was used to provide efficient spatial confinement of the charge carriers, leading to enhanced charges concentration and improved radiative recombination rates. ${ }^{[53]}$

However, during the film growing process, the slow crystallization rate and the easy aggregation of perovskite components make it difficult to achieve a uniform morphology with the film thickness down to around $20 \mathrm{~nm}$. In order to hinder the aggregation process, strategies of introducing anti-solvent or using mixed solvents for the precursors were developed. ${ }^{[107-109]}$ Both processes accelerate the crystallization rate during the film formation process, which generates perovskite film with continuous film morphology and less aggregation. Further investigations on the processing conditions of perovskite films show that the annealing temperature and duration significantly affect the device performance. ${ }^{[110]}$ However, perovskite LEDs based on these films show poor 
EQE around $0.1-2 \%$, implying that the improvement in the morphology is not enough to achieve decent device performance.

\subsection{Perovskite-organic material composites}

Organic materials with high flexibility are ideal materials to hinder the serious aggregation of perovskite components. By mixing perovskite components with organic polymers, e.g. insulating polyimide precursor dielectric (PIP), ${ }^{[11]}$ polyvinylpyrrolidone (PVP), ${ }^{[12]}$, poly(ethylene oxide) $(\mathrm{PEO})^{[113,114]}$ and poly(methyl methacrylate) (PMMA), ${ }^{[115]}$ perovskite-organic matrix films form after deposition process (Figure 5.1 a). This method generates perovskite films with continuous and flat morphology because of the hindered components aggregation. ${ }^{[116]}$ The perovskite grains show decreased crystallinity since the chains of organic molecules hinder perovskite crystals growth (Figure 5.1 b and c). In addition, the incorporated organic materials form encapsulation to the perovskite grains and help to increase films stability against the electric field and moisture. ${ }^{[113]}$ Further research on introducing organic materials with better electronic properties like poly(9-vinylcarbazole) (PVK) and 1,3,5-tris(1-phenyl1H-benzimidazol-2-yl) benzene (TPBi) show promising results on improving the film morphology and achieving better bipolar charge injections. ${ }^{[17]}$

However, most of the organic materials possess low charge carrier mobility, hindering the charge transport within the light-emitting layers. Therefore, a careful control of the perovskite-organic materials ratio and the film deposition are necessary to reach a proper phase separation.
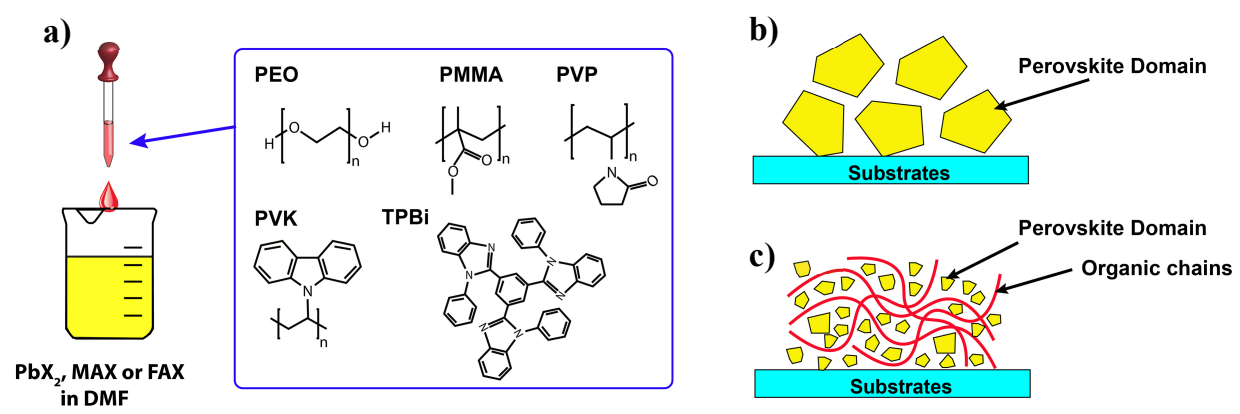

Figure 5.1 a) Perovskite precursor prepared with organic materials; diagram of perovskite domains formed on substrates $b$ ) without and c) with organic matrix. 
Growth control of perovskite light-emitting films

\subsection{Stoichiometry engineering}

As a result of low formation energy of cations and halides vacancies in perovskite films, these shallow traps usually exist in perovskites in a large number. ${ }^{[90]}$ It is therefore natural to provide more cation halides (AX) into perovskite films to heal these defects. Incorporating 1 to $50 \%$ of excess organic halides over $\mathrm{PbX}_{2}$ has been proved efficient in decreasing the defects dramatically, as demonstrated by previous work on perovskite optoelectronic devices. ${ }^{[118,119]}$

Further increasing the stoichiometry ratio of the perovskite precursor helps to release the severe components aggregation. Commonly, perovskite precursor solutions are prepared with a stoichiometric ratio $\left(\mathrm{PbX}_{2}: \mathrm{AX}=1: 1\right)$. In this case, the perovskite components tend to aggregate in the precursor solution by forming large sized intermediate poly-halide colloidal particles. ${ }^{[120]}$ The excess amount of organic halides towards $\mathrm{PbX}_{2}$ decreases the halogen sharing degree, resulting in colloids with smaller sizes in the precursors. The shrinking colloidal sizes in perovskite precursors with increasing stoichiometry ratios are further proven by dynamic light scattering (DLS) measurement, as shown in Figure 5.2.

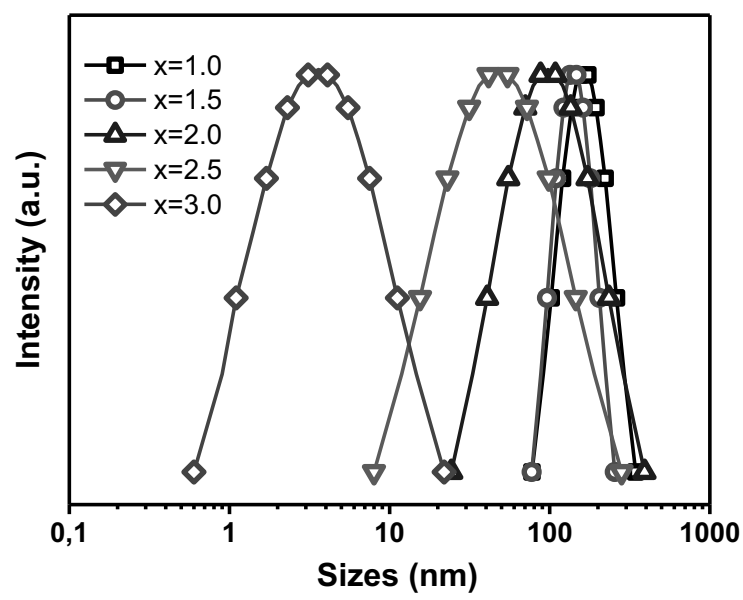

Figure 5.2 DLS results of perovskite precursor solutions that prepared with different stoichiometry. The perovskite precursors are prepared by mixing $(0.1 \mathrm{CsI}+0.9 \mathrm{FAI}): \mathrm{PbI}_{2}$ with different ratios ( $x$ in the Figure)

Although the excess cation halides help to passivate the A site cations or halides vacancies, the dramatical influence of them on perovskite film morphology and electronic properties cannot be ignored. We notice that proper ratios between A site and 
B site cation halides are in the range of 1.5 to 3.0. The stoichiometric control results in formation of perovskite films with decreased crystal sizes down to around $10 \mathrm{~nm}$, which is close to that of perovskite QDs via wet-chemistry synthesis. ${ }^{[121,122]}$ Consequently, the perovskite films processed from precursors with high stoichiometry ratios show much enhanced PLQEs and carrier lifetime. ${ }^{[123,124]}$ Simultaneously, extra amount of cation halides contributes to a more uniform perovskite morphology. ${ }^{[124]}$ In addition, these organic cations provide extra protections to the resulting perovskite crystals, contributing to a better film and device stability. Interestingly, this stoichiometry engineering helps to stabilize black phase ( $\alpha$-phase) of $\mathrm{FAPbI}_{3}$ perovskite films, which is a very important method to tune the $\mathrm{FAPbI}_{3}$ perovskite film properties for efficient light emission. ${ }^{[123]}$

However, further increasing the ratio to 3.0 (or higher) results in aggregation of the organic cations, showing a negative influence on perovskite film formation process by generating large sized clusters. ${ }^{[124]}$ In addition, the excess amount of insulating organic cations also results in poor charge carrier mobility and large series resistance of the perovskite emission layer, hindering efficient charge injections. ${ }^{[123,124]}$

Instead of using AX (MAX, FAX or CsX), the stoichiometry engineering can also be implemented by introducing extra amount of long chain-ammonium halides into the perovskite film. This long chain materials contribute to the formation of small sized perovskite nanocrystals and self-assemble at the surface of perovskite crystals, blocking the ion migration under electrical stress and passivating defects at the crystal surface. $[125,126]$

\subsection{Perovskite dimension engineering}

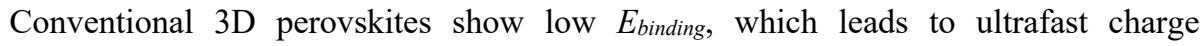
dissociation rate at room temperature and high performance in solar cells. [95, 127] However, when these 3D perovskites are used as light-emitting materials, they show low bimolecular recombination rates of the charge carriers. Consequently, trap assisted recombination becomes a dominant process under low charge densities and results in poor PLQEs of the perovskite films. By decreasing the dimension of bulky perovskite down to 2D, or even 0D helps to increase the Ebinding to over $470 \mathrm{meV}$, which further accelerates the monomolecular radiative recombination. ${ }^{[25,128]}$ 
Growth control of perovskite light-emitting films

\subsubsection{Quasi-2D perovskites}

By blending large-sized organic cation halides $\left(\mathrm{RNH}_{3} \mathrm{I}\right), \mathrm{AX}(\mathrm{A}$ : Cs, FA or MA) and $\mathrm{PbX}_{2}$ (X: $\mathrm{Cl}, \mathrm{Br}$ or $\mathrm{I}$ ) with different stoichiometry ratios, films with different $2 \mathrm{D}$ perovskite thickness ( $\boldsymbol{n}$ values) can be obtained. ${ }^{[129]}$ In addition, the organic ligands staying outside of the 2D perovskite show low dielectric constant and large bandgaps, while the inorganic octahedral sheets have high dielectric constant and low bandgaps. The large difference in dielectric constants and bandgap contribute to the formation of quantum wells structure (as shown in Figure 5.3a). These quantum wells increase the $E_{\text {binding }}$ and efficiently confine charge carriers. Moreover, it also leads to obvious blue shift of the emission spectra, which can be used as an efficient way to tune the emission colors of perovskite LEDs. ${ }^{[22]}$ Note that precisely controlling the $\boldsymbol{n}$ values is still a challenge due to the imbalanced perovskite crystallization rate during film formation process. ${ }^{[130]}$ Instead, one can obtain self-organized perovskite films with different $n$ values, which is the well-known perovksite multiple quantum wells (MQWs). Due to this unique structure of MQWs, efficient energy transfer from small $\boldsymbol{n}$ value (or large bandgap) perovskites to large $\boldsymbol{n}$ value (or narrow bandgap) perovskites, leading to accumulated charge carriers in perovskites with the narrowest bandgap (as shown in Figure 5. 3b), generating efficient EL even at low charge injection levels. ${ }^{[78,131,132]}$ High EQE values of over $20 \%$ have been achieved in NIR region and they also show great potential in achieving high performance blue and red LEDs. ${ }^{[10-12]}$

a)

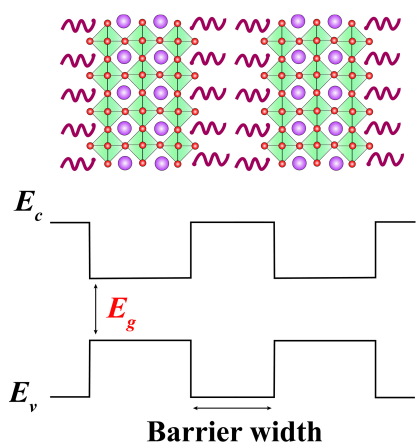

b)

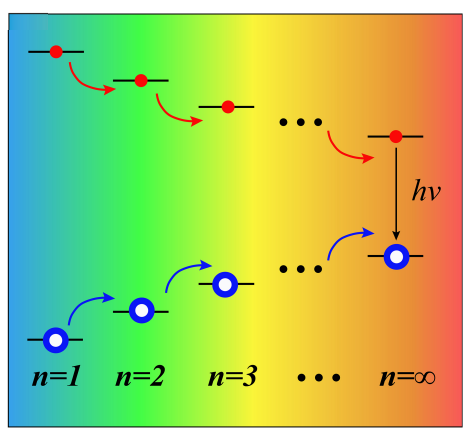

Figure 5.3 a) Energy level diagram of the 2D perovskite structure; b) Schematic diagram of the energy-transfer process in perovskite MQWs film. 


\subsubsection{Perovskite QDs}

Further decreasing the 3D perovskites dimension, one can obtain the perovskite NWs. (1D) or perovskite QDs (0D). By tuning the halide compositions of perovskite QDs, emission ranging from purple to NIR region can be achieved. ${ }^{[29]}$ Besides, perovskite QDs show high PLQEs up to $95 \%$ and narrower emission comparing to their 2D or 3D counterparts. ${ }^{[109]}$ Together with the easy synthesis process in large scale, perovskite QDs are promising for the fabrication of low cost and high-performance LEDs. The state-ofthe-art LEDs based on perovskite QDs have achieved a high EQE of over $20 \%$, among the highest reported performance of perovskite LEDs. ${ }^{[32]}$

High quality perovskite QDs can be prepared via wet chemistry colloidal synthesis, e.g. ligand-assisted reprecipitation and hot injection process. ${ }^{[29]}$ In addition, the obtained perovskite QDs can be easily dispersed in a non-polar solvent, e.g. toluene and chlorobenzene (CB), making them compatible with large area printing techniques. What's more, the perovskite QDs covered with organic ligands show improved stability against moisture because of the hydrophobic nature of the ligands.

\subsection{Interface}

\subsubsection{Interface and interface modifications}

The buried interfaces have a big influence on the perovskite film growth. Firstly, it is believed that a hydrophilic interface contributes to the formation of perovskite active layer with more continuous film morphology. Although most polymer HILs show poor surface wettability with the perovskite precursor solution, hydrophilic surfaces can be achieved for facile perovskite film deposition by treating the polymer films with oxygen $\left(\mathrm{O}_{2}\right)$ plasma. ${ }^{[124]}$ In addition, modifications of the interface materials improve the wettability, inducing different crystallization process of perovskite films on top and contributing to improved quality of the light-emitting layer. ${ }^{[133]}$

Secondly, energy levels of the interfacial layers affect the charge injection process and the device performance of perovskite LEDs. In order to achieve an efficient radiative recombination within the emission layer, fast and barrier free charge injections are perquisites. A mismatch of energy levels between the charge injection interlayers and the perovskite emitting layers causes charge injection barriers, leading to high $V_{\text {turn-on }}$ of LEDs. Solution processed metal oxides like $\mathrm{ZnO}, \mathrm{TiO}_{\mathrm{x}}$ and $\mathrm{NiO}_{\mathrm{x}}$ are commonly used interlayers for perovskite optoelectronic devices. However, these materials show mismatched energy levels with the perovskite light-emitting layers and contain 
significant defects when processed at a relatively low temperature. ${ }^{[8,134,135]}$ Fortunately, these issues can be overcome by using additional interfacial layers to modify the metal oxides, which contributes to better interfacial contacts. The widely used modification materials are polyethylenimine ethoxylated (PEIE), ${ }^{[10,}{ }^{136]}$ polyethylenimine (PEI), ${ }^{[8]}$ ethanolamine (EA) ${ }^{[137]}$ amino acid ${ }^{[138]}$ and perfluorinated ionomer $(\mathrm{PFI})^{[139]}$ etc., which tunes the energy level structures and also helps to passivate the defects at the charge injection interfaces.

Apart from the effects of the substrates wettability and energy levels, mobilities of the charge injection layers are also important factors to be considered when preparing LEDs. ${ }^{[2]}$ Unbalanced charge injection leads to the accumulation of space charge on one side of the device, resulting in non-radiative Auger recombination. In order to reach a balance between electron and hole injection, EIL and HIL materials with similar charge carrier mobilities are preferred. In addition, this balance can also be achieved by tuning the mobility of charge injection layer by controllable chemical doping or introducing charge blocking layer. ${ }^{[119,140]}$

\subsubsection{Interface assisted deprotonation of organic cations}

Previous results have shown that the buried interfacial layers significantly affect the perovskite film growing process and qualities. ${ }^{[141,142]}$ However, since organic cations of hybrid perovskites can easily decompose under certain conditions, the deprotonation process induced by basic interfacial materials affects the perovskite film quality.

$\mathrm{ZnO}$ is an excellent electron transport (or injection) material and has achieved excellent performance in organic and QDs optoelectronics device because of its high electron mobility, high transparency and proper energy levels. ${ }^{[143,144]}$ However, utilizing ZnO as the charge transport layer in perovskite solar cells show inferior performance to the ones based on $\mathrm{SnO}_{2}$ and $\mathrm{TiO}_{2}{ }^{\left[{ }^{[81]}\right.} \mathrm{In}$ addition, $\mathrm{ZnO}$ also triggers the decomposition of perovskite, leading to decreased operational lifetime.

The reason of the fast degradation of perovskite on the $\mathrm{ZnO}$ substrate is the basic surface properties of $\mathrm{ZnO}$. When depositing MA or FA based hybrid perovskites on the $\mathrm{ZnO}$ surface directly, a fast deprotonation process of organic cations happens, which is described as,

$$
\mathrm{MA}^{+} \stackrel{\mathrm{ZnO}}{\longrightarrow} \mathrm{MA} \uparrow+\mathrm{H}^{+}
$$

The deprotonation process results in the formation of MA gas, which leaves the film during thermal annealing process. Here the decomposition of $\mathrm{MAPbI}_{3}$ can be represented as, 
Growth control of perovskite light-emitting films

$$
\mathrm{MAPbI}_{3} \stackrel{\text { Zno }}{\longrightarrow} \mathrm{MA} \uparrow+\mathrm{HI} \uparrow+\mathrm{PbI}_{2}
$$

The chemical function groups on the $\mathrm{ZnO}$ surface, e.g. hydroxyl groups, also contribute to the fast deprotonation process. ${ }^{[141]}$ In addition, FA based perovskites are more stable on $\mathrm{ZnO}$ substrates compared to their MA counterparts. ${ }^{[145,146]}$

Since the deprotonation process deteriorates perovskite films quality and device performance, the perovskite solar cell community have taken efforts to hinder the reaction rate by inserting another interfacial layer, e.g. [6,6]-phenyl-C61-butyric acid methyl ester (PC $\left.{ }_{61} \mathrm{BM}\right)$, PEI, self-assembled monolayer (SAM) and thin layer of other metal oxide (Magnesium oxide or Aluminium oxide). ${ }^{[141,147,148]}$ In addition, doping or alloying $\mathrm{ZnO}$ with magnesium $(\mathrm{Mg}$ ) or aluminium (Al) helps to decrease the basicity of $\mathrm{ZnO}$ films, hindering the fast deprotonation process. ${ }^{[149]}$ 


\section{Chapter 6}

\section{Conclusion and outlook}

Metal halide perovskites are emerging as promising semiconductors for cost-effective and high-performance LEDs. During the past five years, EQE of perovskite LEDs has been improved to over $21 \%$, demonstrating an attractive application potential in the future. Importantly, the perovskites exhibit ultra-pure light emission, which is a key property for achieving vivid displays. However, the performance of perovskite LEDs still lags behind state-of-the-art OLEDs and QLEDs technologies in the market. Especially, the performance of blue- and red-emissive perovskite LEDs are still lower than that of green and NIR ones. Precise material control, efficient defects passivation and novel design of the device structures may contribute to further performance improvement. $[130,150,151]$

In addition, perovskite-based LEDs still exhibit a relatively poor operational stability, which is primarily caused by the environmental instability of perovskites. ${ }^{[53]}$ Allinorganic or mixed-cation hybrid perovskites with better thermal stability have already shown enhanced operational stability in the perovskite LEDs, making them promising candidates for the fabrication of stable perovskites LEDs. ${ }^{[152]}$ Another stability issue which needs to be considered for perovskite LEDs is the moisture and oxygen induced degradation of perovskites. Efficient encapsulation techniques are possibly helpful to prolong the devices lifetime.

In addition to the environmental factors, intrinsic ion migration of perovskites is a critical issue that may cause decomposition of perovskites under device working condition. ${ }^{[54,153]}$ Although there are many reports on the effects of ion migration on the stability of perovskite solar cells, the influence of ion migration on perovskite LEDs is rarely reported. ${ }^{[154,155]}$ Further efforts are required to understand the impact of ion migration on perovskite LEDs.

Another concern on the toxicity of $\mathrm{Pb}$ leads to the research on pursuing lead-free perovskites for LED applications. Although the demonstrated lead-free perovskites show poor performance in the LEDs currently, the research on lead-free perovskites has 


\section{Conclusion and outlook}

achieved many interesting results. ${ }^{[156]}$ For example, double perovskite $\mathrm{Cs}_{2} \mathrm{AgInCl}_{6}$ alloyed with $\mathrm{NaCl}$ show attractive PLQEs up to $86 \%$, close to the best Pb-based perovskite QDs. ${ }^{[69]}$ Apparently, continuous research on these double perovskite family is attractive and will hopefully bring us surprises in the future. 


\section{Chapter 7}

\section{Paper summary}

\section{Paper 1}

Title: Deoxyribonucleic acid (DNA) molecule as a processing additive for efficient perovskite light-emitting diodes
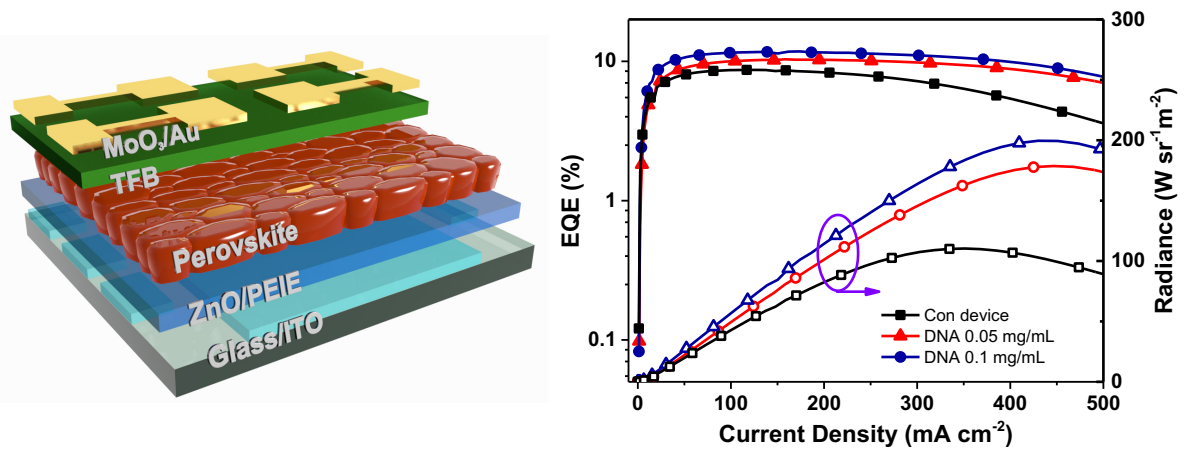

In this manuscript, we introduce deoxyribonucleic acid (DNA), which is one of the most representative biomolecules, into the emissive layer of perovskite LEDs. Here we use formamidinium lead iodide $\left(\mathrm{FAPbI}_{3}\right)$ as the light-emissive layer. After the incorporation of DNA molecules, we observe pin-hole free and smooth perovskite film morphology. What's more, the phosphate and carbonyl groups of DNA molecules contribute to the passivation of defects state at the perovskite crystal surface, which leads to improved PLQEs and longer carrier lifetime of perovskite films. This passivating role of DNA is further evidenced by FTIR results. As a result, we achieve perovskite LEDs with a peak EQE of $11.9 \%$ based on formamidinium perovskite $\left(\mathrm{FAPbI}_{3}\right)$, which is over $30 \%$ improvement compared to the control devices without any DNA incorporation. 


\section{Paper 2}

Title: Rational molecular passivation for high-performance perovskite lightemitting diodes

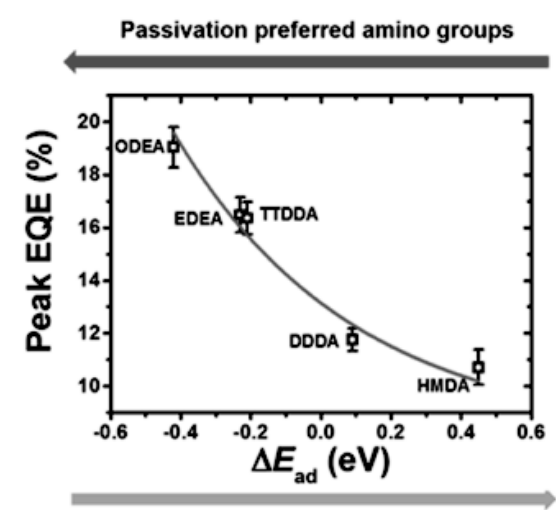

Hydrogen bonding preferred amino groups

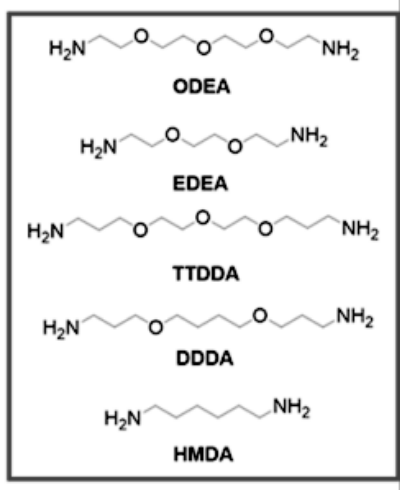

The passivation agents

Here in this manuscript, we incorporate amino-functionalized passivation agents to heal the defects in perovskite films. We notice that passivation agents forming strong hydrogen bonds with organic cations in perovskites are not able to mediate the defects effectively. In order to decrease hydrogen-bonding ability of passivation agents, we tune the number of $\mathrm{O}$ atoms and the length of alkyl chain within the passivation agents to polarize the passivating amino groups via the inductive effect, which consequently reduces electron-donating ability of $\mathrm{O}$ atoms. We notice much enhanced coordination of the passivation agents with the perovskite defect sites and much improved PLQE of the perovskite films, indicating a decreased amount of trap-mediated non-radiative recombination. With the new passivation agents, we obtain much improved device performance of perovskite LEDs, giving a record EQE of $21.6 \%$. In addition, we observe minimum efficiency roll-off of perovskite LEDs even at a high current density of $200 \mathrm{~mA} \mathrm{~cm}^{-2}$. 


\section{Paper 3}

Title: Room-Temperature Film Formation of Metal Halide Perovskites on n-type Metal Oxides: The Catalysis of $\mathrm{ZnO}$ on Perovskite Crystallization

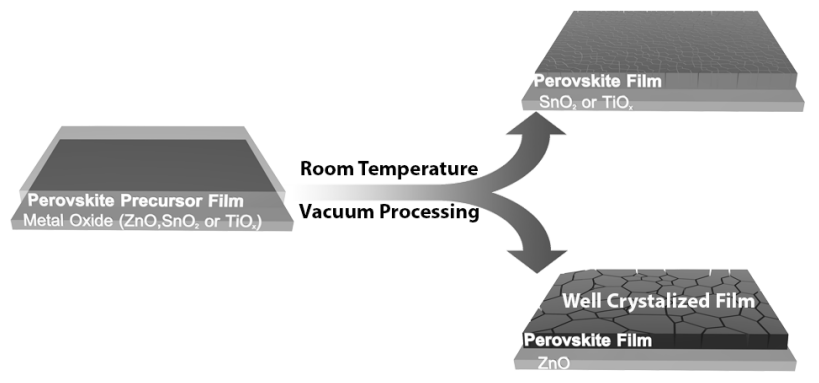

Herein, we studied the film growing process of $\mathrm{MAPbI}_{3}$ perovskite on different metal oxide electron transporting layers, i.e. $\mathrm{TiO}_{\mathrm{x}}, \mathrm{SnO}_{2}$, and $\mathrm{ZnO}$. In order to avoid the fast degradation of perovskite on $\mathrm{ZnO}$ substrate at high temperature, we used a vacuumprocessing at room temperature to dry perovskite films after spin-coating process. We notice that only the films deposited on $\mathrm{ZnO}$ show much enhanced crystallinity, while the crystallization of $\mathrm{MAPbI}_{3}$ perovskite on other two substrates is much retarded. Enhanced PL emission, obvious absorption shoulder at $750 \mathrm{~nm}$ in UV-vis absorption spectra and improved device performance indicate the excellent properties of the perovskite films on $\mathrm{ZnO}$ substrate. Our results suggest that the reaction at the $\mathrm{ZnO}$ /perovskite interface contribute to the transition from intermediate states to highly crystalized perovskites. 


\section{Paper 4}

Title: Unveiling the synergistic effects of precursor stoichiometry and interfacial reaction for high-performance perovskite light-emitting diodes

a

$$
\underset{0}{\infty}\left[\mathrm{Pbl}_{6}\right]^{4} \quad \mathrm{~g}^{2} \mathrm{FA}^{+} \circ \mathrm{Cs}^{+} \circ 1^{-}
$$

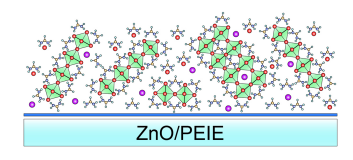

b

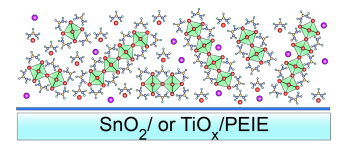

Thermal Annealing process

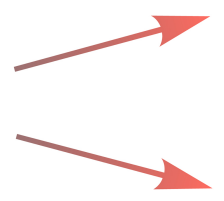

As-deposited precursor complex $(x=2.5)$

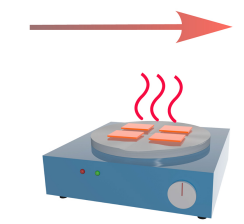

c

d
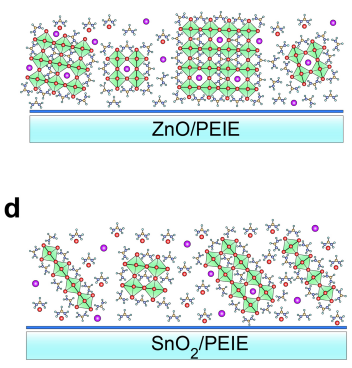

e

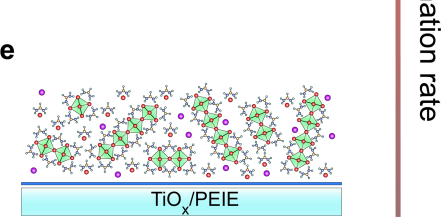

Thermal annealled perovskite film

In this manuscript, we reveal that an efficient deprotonation of the undesirable organic cations $\left(\mathrm{FA}^{+}\right)$by a basic metal oxide interlayer is critical to promote the transition from perovskite in intermediate phases to highly emissive perovskite crystals. We also demonstrate that this deprotonation process is not hindered by further defect passivation with amino-functionalized molecules. Combining our findings of organic cation deprotonation with effective defects passivation in the perovskite light-emissive films, we achieve a maximum EQE of $19.6 \%$ and a high radiance of $301.8 \mathrm{~W} \mathrm{sr}^{-1} \mathrm{~m}^{-2}$. Our results here offer new understandings for the controllable growth of high-quality perovskite films on substrates with different surface properties. 


\section{Paper 5}

Title: Deprotonation assisted mixed-cation perovskite crystallization for efficient light-emitting diodes

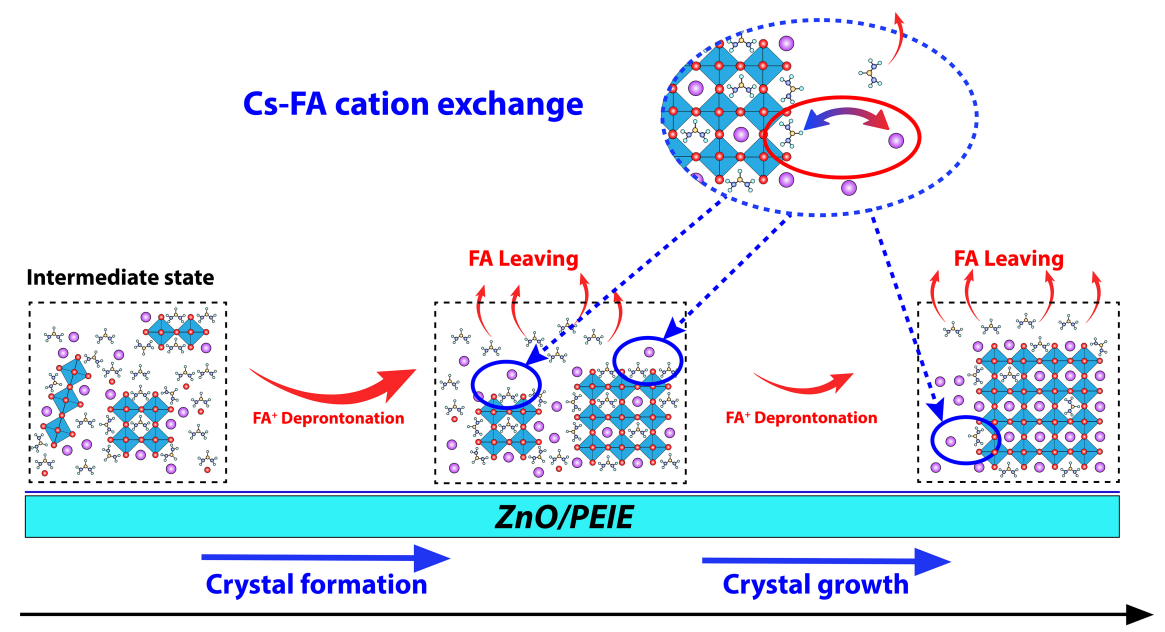

Thermal annealing duration time (s)

Here in this manuscript, we incorporate extra amounts of formamidinium iodide (FAI) molecular $\left(50 \%, 100 \%, 150 \%\right.$ and $200 \%$ of the amount of $\left.\mathrm{PbI}_{2}\right)$ into the all-inorganic $\mathrm{CsPbI}_{3}$ perovskite precursor to form over stoichiometric solutions. We deposit the perovskite precursors on $\mathrm{ZnO} / \mathrm{PEIE}$ substrates. After the thermal annealing process (120 ${ }^{\circ} \mathrm{C}$ ), we notice that excess amounts of FAI promote much-enhanced crystallinity of perovskite. When $150 \%$ of FAI is introduced, we achieve perovskite LEDs with a peak EQE of $15.9 \%$ and a radiance of $320 \mathrm{~W} \mathrm{sr}^{-1} \mathrm{~m}^{-2}$ with $150 \%$ of FAI in the perovskite precursor solution. In order to further study the film growing process, we conduct insitu steady-state PL measurements on perovskite film (150\% FAI based perovskite film) during thermal annealing process. We observe that the PL peaks of perovskite film show red shifts from around $680 \mathrm{~nm}$ to $740 \mathrm{~nm}$ at the beginning of thermal annealing process. After that continuous blue shifts are observed. The PL peaks stabilize at around $715 \mathrm{~nm}$ after 3 min annealing process. Together with XRD and UV-vis absorption results, we reveal that a Cs-FA cations exchange process happens in the perovskite films, leading to a transition from FA rich perovskites to Cs-rich ones. Consequently, the device shows a brightness of $800 \mathrm{~cd} \mathrm{~m}^{-2}$ with the light emission peaks at approximately $715 \mathrm{~nm}$. 
Reference 
Reference

\section{Reference}

[1] R. M. Rowlett, Acta Anthropologica Sinica 2000, 19, 198.

[2] X. Dai, Z. Zhang, Y. Jin, Y. Niu, H. Cao, X. Liang, L. Chen, J. Wang, X. Peng, Nature 2014, 515, 96.

[3] R. Braunstein, Physical Review 1955, 99, 1892.

[4] P. Schlotter, J. Baur, C. Hielscher, M. Kunzer, H. Obloh, R. Schmidt, J. Schneider, Materials Science and Engineering: B 1999, 59, 390.

[5] M. Saliba, J.-P. Correa-Baena, M. Grätzel, A. Hagfeldt, A. Abate, Angew. Chem. Int. Ed. 2018, 57, 2554.

[6] S. D. Stranks, H. J. Snaith, Nat. Nanotech. 2015, 10, 391.

[7] Z. Song, C. L. McElvany, A. B. Phillips, I. Celik, P. W. Krantz, S. C. Watthage, G. K. Liyanage, D. Apul, M. J. Heben, Energy Environ. Sci. 2017, 10, 1297.

[8] J. Wang, N. Wang, Y. Jin, J. Si, Z. K. Tan, H. Du, L. Cheng, X. Dai, S. Bai, H. He, Adv. Mater. 2015, 27, 2311.

[9] Z.-K. Tan, R. S. Moghaddam, M. L. Lai, P. Docampo, R. Higler, F. Deschler, M. Price, A. Sadhanala, L. M. Pazos, D. Credgington, Nat. Nanotech. 2014, 9, 687.

[10] Y. Cao, N. Wang, H. Tian, J. Guo, Y. Wei, H. Chen, Y. Miao, W. Zou, K. Pan, Y. He, Nature 2018, 562, 249.

[11] K. Lin, J. Xing, L. N. Quan, F. P. G. de Arquer, X. Gong, J. Lu, L. Xie, W. Zhao, D. Zhang, C. Yan, W. Li, X. Liu, Y. Lu, J. Kirman, E. H. Sargent, Q. Xiong, Z. Wei, Nature 2018, 562, 245.

[12] B. Zhao, S. Bai, V. Kim, R. Lamboll, R. Shivanna, F. Auras, J. M. Richter, L. Yang, L. Dai, M. Alsari, X.-J. She, L. Liang, J. Zhang, S. Lilliu, P. Gao, H. J. Snaith, J. Wang, N. C. Greenham, R. H. Friend, D. Di, Nat. Photon. 2018, 12, 783.

[13] G. Xing, N. Mathews, S. Sun, S. S. Lim, Y. M. Lam, M. Grätzel, S. Mhaisalkar, T. C. Sum, Science 2013, 342, 344.

[14] M. M. Lee, J. Teuscher, T. Miyasaka, T. N. Murakami, H. J. Snaith, Science 2012, $338,643$.

[15] Y.-M. You, W.-Q. Liao, D. Zhao, H.-Y. Ye, Y. Zhang, Q. Zhou, X. Niu, J. Wang, P.-F. Li, D.-W. Fu, Science 2017, 357, 306.

[16] J. H. Kim, Y. Jo, J. H. Kim, J. W. Jang, H. J. Kang, Y. H. Lee, D. S. Kim, Y. Jun, J. S. Lee, ACS Nano 2015, 9, 11820. 


\section{Reference}

[17] M. Saliba, T. Matsui, J.-Y. Seo, K. Domanski, J.-P. Correa-Baena, M. K. Nazeeruddin, S. M. Zakeeruddin, W. Tress, A. Abate, A. Hagfeldt, Energy Environ. Sci. 2016, 9, 1989.

[18] M. Saliba, T. Matsui, K. Domanski, J.-Y. Seo, A. Ummadisingu, S. M. Zakeeruddin, J.-P. Correa-Baena, W. R. Tress, A. Abate, A. Hagfeldt, Science 2016, 354, 206.

[19] D. B. Mitzi, J. Chem. Soc., Dalton Trans. 2001, 1.

[20] W. Travis, E. N. K. Glover, H. Bronstein, D. O. Scanlon, R. G. Palgrave, Chem. Sci. 2016, 7, 4548.

[21] Z. Li, M. Yang, J.-S. Park, S.-H. Wei, J. J. Berry, K. Zhu, Chem. Mater. 2016, 28, 284.

[22] B. Saparov, D. B. Mitzi, Chem. Rev. 2016, 116, 4558.

[23] H. Tsai, W. Nie, J.-C. Blancon, C. C. Stoumpos, R. Asadpour, B. Harutyunyan, A. J. Neukirch, R. Verduzco, J. J. Crochet, S. Tretiak, Nature 2016, 536, 312.

[24] R. Yang, R. Li, Y. Cao, Y. Wei, Y. Miao, W. L. Tan, X. Jiao, H. Chen, L. Zhang, Q. Chen, H. Zhang, W. Zou, Y. Wang, M. Yang, C. Yi, N. Wang, F. Gao, C. R. McNeill, T. Qin, J. Wang, W. Huang, Adv. Mater. 2018, 30, 1804771.

[25] J. C. Blancon, A. V. Stier, H. Tsai, W. Nie, C. C. Stoumpos, B. Traoré, L. Pedesseau, M. Kepenekian, F. Katsutani, G. T. Noe, J. Kono, S. Tretiak, S. A. Crooker, C. Katan, M. G. Kanatzidis, J. J. Crochet, J. Even, A. D. Mohite, Nat. Commun. 2018, 9, 2254.

[26] D. Zhang, S. W. Eaton, Y. Yu, L. Dou, P. Yang, J. Am. Chem. Soc. 2015, 137, 9230.

[27] X. Peng, L. Manna, W. Yang, J. Wickham, E. Scher, A. Kadavanich, A. P. Alivisatos, Nature 2000, 404, 59.

[28] S. A. McDonald, G. Konstantatos, S. Zhang, P. W. Cyr, E. J. Klem, L. Levina, E. H. Sargent, Nat. Mater. 2005, 4, 138.

[29] F. Zhang, H. Zhong, C. Chen, X.-g. Wu, X. Hu, H. Huang, J. Han, B. Zou, Y. Dong, ACS Nano 2015, 9, 4533.

[30] J. Song, J. Li, X. Li, L. Xu, Y. Dong, H. Zeng, Adv. Mater. 2015, 27, 7162.

[31] NREL, https://www.nrel.gov/pv/assets/pdfs/best-research-cell-efficiencies190416. pdf, 2019.

[32] T. Chiba, Y. Hayashi, H. Ebe, K. Hoshi, J. Sato, S. Sato, Y.-J. Pu, S. Ohisa, J. Kido, Nat. Photon. 2018, 12, 681.

[33] Q. Chen, J. Wu, X. Ou, B. Huang, J. Almutlaq, A. A. Zhumekenov, X. Guan, S. Han, L. Liang, Z. Yi, J. Li, X. Xie, Y. Wang, Y. Li, D. Fan, D. B. L. Teh, A. H. All, O. F. Mohammed, O. M. Bakr, T. Wu, M. Bettinelli, H. Yang, W. Huang, X. Liu, Nature 2018, 561,88 . 


\section{Reference}

[34] C. Bao, J. Yang, S. Bai, W. Xu, Z. Yan, Q. Xu, J. Liu, W. Zhang, F. Gao, Adv. Mater. 2018, 30, 1870288.

[35] Z. Li, J. Moon, A. Gharajeh, R. Haroldson, R. Hawkins, W. Hu, A. Zakhidov, Q. Gu, ACS Nano 2018, 12, 10968.

[36] H. Zhu, A. Liu, H. L. Luque, H. Sun, D. Ji, Y.-Y. Noh, ACS Nano 2019, 13, 3971.

[37] R. E. Brandt, V. Stevanović, D. S. Ginley, T. Buonassisi, Mrs Communications 2015, 5, 265.

[38] M. V. Kovalenko, L. Protesescu, M. I. Bodnarchuk, Science 2017, 358, 745.

[39] V. K. Ravi, G. B. Markad, A. Nag, ACS Energy Lett. 2016, 1, 665.

[40] Q. A. Akkerman, V. D’Innocenzo, S. Accornero, A. Scarpellini, A. Petrozza, M. Prato, L. Manna, J. Am. Chem. Soc. 2015, 137, 10276.

[41] G. Nedelcu, L. Protesescu, S. Yakunin, M. I. Bodnarchuk, M. J. Grotevent, M. V. Kovalenko, Nano Lett. 2015, 15, 5635.

[42] F. Hao, C. C. Stoumpos, R. P. H. Chang, M. G. Kanatzidis, J. Am. Chem. Soc. 2014, 136, 8094.

[43] M. Xiao, F. Huang, W. Huang, Y. Dkhissi, Y. Zhu, J. Etheridge, A. Gray-Weale, U. Bach, Y. B. Cheng, L. Spiccia, Angew. Chem. Int. Ed. 2014, 53, 9898.

[44] N. J. Jeon, J. H. Noh, Y. C. Kim, W. S. Yang, S. Ryu, S. I. Seok, Nat. Mater. 2014, 13,897 .

[45] F. Huang, Y. Dkhissi, W. Huang, M. Xiao, I. Benesperi, S. Rubanov, Y. Zhu, X. Lin, L. Jiang, Y. Zhou, Nano Energy 2014, 10, 10.

[46] D. Liu, T. L. Kelly, Nat. Photon. 2014, 8, 133.

[47] Z. Xiao, Q. Dong, C. Bi, Y. Shao, Y. Yuan, J. Huang, Adv. Mater. 2014, 26, 6503.

[48] Q. Chen, H. Zhou, Z. Hong, S. Luo, H.-S. Duan, H.-H. Wang, Y. Liu, G. Li, Y. Yang, J. Am. Chem. Soc. 2013, 136, 622.

[49] M. Liu, M. B. Johnston, H. J. Snaith, Nature 2013, 501, 395.

[50] S. Razza, S. Castro-Hermosa, A. D. Carlo, T. M. Brown, APL Mater. 2016, 4, 091508.

[51] D. Bryant, N. Aristidou, S. Pont, I. Sanchez-Molina, T. Chotchunangatchaval, S. Wheeler, J. R. Durrant, S. A. Haque, Energy Environ. Sci. 2016, 9, 1655.

[52] T. A. Berhe, W.-N. Su, C.-H. Chen, C.-J. Pan, J.-H. Cheng, H.-M. Chen, M.-C. Tsai, L.-Y. Chen, A. A. Dubale, B.-J. Hwang, Energy Environ. Sci. 2016, 9, 323.

[53] L. Zhao, K. M. Lee, K. Roh, S. U. Z. Khan, B. P. Rand, Adv. Mater. 2019, 1805836.

[54] H. Lee, D. Ko, C. Lee, ACS Appl. Mater. \& Interfaces 2019, 11, 11667.

[55] C. Eames, J. M. Frost, P. R. F. Barnes, B. C. O’Regan, A. Walsh, M. S. Islam, Nat. Commun. 2015, 6, 7497.

[56] H. Cho, Y.-H. Kim, C. Wolf, H.-D. Lee, T.-W. Lee, Adv. Mater. 2018, 30, 1704587. 


\section{Reference}

[57] G. E. Eperon, G. M. Paterno, R. J. Sutton, A. Zampetti, A. A. Haghighirad, F. Cacialli, H. J. Snaith, J. Mater. Chem. A 2015, 3, 19688.

[58] T. Zhang, M. I. Dar, G. Li, F. Xu, N. Guo, M. Grätzel, Y. Zhao, Science advances 2017, 3, e1700841.

[59] X. Zheng, C. Wu, S. K. Jha, Z. Li, K. Zhu, S. Priya, ACS Energy Lett. 2016, 1, 1014.

[60] A. Swarnkar, A. R. Marshall, E. M. Sanehira, B. D. Chernomordik, D. T. Moore, J. A. Christians, T. Chakrabarti, J. M. Luther, Science 2016, 354, 92.

[61] G. Li, F. W. R. Rivarola, N. J. L. K. Davis, S. Bai, T. C. Jellicoe, F. de la Peña, S. Hou, C. Ducati, F. Gao, R. H. Friend, N. C. Greenham, Z.-K. Tan, Adv. Mater. 2016, 28,3528 .

[62] S. Draguta, O. Sharia, S. J. Yoon, M. C. Brennan, Y. V. Morozov, J. S. Manser, P. V. Kamat, W. F. Schneider, M. Kuno, Nat. Commun. 2017, 8, 200.

[63] C. G. Bischak, C. L. Hetherington, H. Wu, S. Aloni, D. F. Ogletree, D. T. Limmer, N. S. Ginsberg, Nano Lett. 2017, 17, 1028.

[64] A. Babayigit, A. Ethirajan, M. Muller, B. Conings, Nat. Mater. 2016, 15, 247.

[65] F. Hao, C. C. Stoumpos, D. H. Cao, R. P. H. Chang, M. G. Kanatzidis, Nat. Photon. 2014, 8, 489.

[66] B. W. Park, B. Philippe, X. Zhang, H. Rensmo, G. Boschloo, E. M. Johansson, Adv. Mater. 2015, 27, 6806.

[67] B. Saparov, F. Hong, J.-P. Sun, H.-S. Duan, W. Meng, S. Cameron, I. G. Hill, Y. Yan, D. B. Mitzi, Chem. Mater. 2015, 27, 5622.

[68] A. H. Slavney, T. Hu, A. M. Lindenberg, H. I. Karunadasa, J. Am. Chem. Soc. 2016, 138, 2138.

[69] J. Luo, X. Wang, S. Li, J. Liu, Y. Guo, G. Niu, L. Yao, Y. Fu, L. Gao, Q. Dong, C. Zhao, M. Leng, F. Ma, W. Liang, L. Wang, S. Jin, J. Han, L. Zhang, J. Etheridge, J. Wang, Y. Yan, E. H. Sargent, J. Tang, Nature 2018, 563, 541.

[70] W. Ning, F. Wang, B. Wu, J. Lu, Z. Yan, X. Liu, Y. Tao, J.-M. Liu, W. Huang, M. Fahlman, L. Hultman, T. C. Sum, F. Gao, Adv. Mater. 2018, 30, 1706246.

[71] C. Wu, Q. Zhang, Y. Liu, W. Luo, X. Guo, Z. Huang, H. Ting, W. Sun, X. Zhong, S. Wei, S. Wang, Z. Chen, L. Xiao, Adv. Sci. 2018, 5, 1700759.

[72] G. He, O. Schneider, D. Qin, X. Zhou, M. Pfeiffer, K. Leo, J. Appl. Phys. 2004, 95, 5773.

[73] X.-B. Shi, Y. Liu, Z. Yuan, X.-K. Liu, Y. Miao, J. Wang, S. Lenk, S. Reineke, F. Gao, Adv. Opt. Mater. 2018, 6, 1800667.

[74] Y.-J. Lee, S.-H. Kim, J. Huh, G.-H. Kim, Y.-H. Lee, S.-H. Cho, Y.-C. Kim, Y. R. Do, Appl. Phys. Lett. 2003, 82, 3779.

[75] S. Möller, S. Forrest, J. Appl. Phys. 2002, 91, 3324. 


\section{Reference}

[76] A. Dodabalapur, L. Rothberg, T. Miller, E. Kwock, Appl. Phys. Lett. 1994, 64, 2486.

[77] Y. Shen, L.-P. Cheng, Y.-Q. Li, W. Li, J.-D. Chen, S.-T. Lee, J.-X. Tang, Adv. Mater., 0, 1901517.

[78] N. Wang, L. Cheng, R. Ge, S. Zhang, Y. Miao, W. Zou, C. Yi, Y. Sun, Y. Cao, R. Yang, Nat. Photon. 2016, 10, 699.

[79] S. Bai, Z. Wu, X. Wu, Y. Jin, N. Zhao, Z. Chen, Q. Mei, X. Wang, Z. Ye, T. Song, R. Liu, S.-t. Lee, B. Sun, Nano Research 2014, 7, 1749.

[80] P. Docampo, J. M. Ball, M. Darwich, G. E. Eperon, H. J. Snaith, Nat. Commun. 2013, 4, 2761.

[81] Q. Jiang, L. Zhang, H. Wang, X. Yang, J. Meng, H. Liu, Z. Yin, J. Wu, X. Zhang, J. You, Nat. Energy 2016, 2, 16177.

[82] L. O. Pålsson, A. P. Monkman, Adv. Mater. 2002, 14, 757.

[83] J. C. de Mello, H. F. Wittmann, R. H. Friend, Adv. Mater. 1997, 9, 230.

[84] R. Minnes, M. Nissinmann, Y. Maizels, G. Gerlitz, A. Katzir, Y. Raichlin, Sci. Rep. 2017, 7, 4381 .

[85] A. L. Patterson, Phys. Rev. 1939, 56, 978.

[86] D. Shi, V. Adinolfi, R. Comin, M. Yuan, E. Alarousu, A. Buin, Y. Chen, S. Hoogland, A. Rothenberger, K. Katsiev, Y. Losovyj, X. Zhang, P. A. Dowben, O. F. Mohammed, E. H. Sargent, O. M. Bakr, Science 2015, 347, 519.

[87] J. M. Ball, A. Petrozza, Nat. Energy 2016, 1, 16149.

[88] D. W. de Quilettes, S. M. Vorpahl, S. D. Stranks, H. Nagaoka, G. E. Eperon, M. E. Ziffer, H. J. Snaith, D. S. Ginger, Science 2015, 348, 683.

[89] M. A. Reshchikov, H. Morkoç, J. Appl. Phys. 2005, 97, 5.

[90] A. Buin, R. Comin, J. Xu, A. H. Ip, E. H. Sargent, Chem. Mater. 2015, 27, 4405.

[91] M. L. Agiorgousis, Y.-Y. Sun, H. Zeng, S. Zhang, J. Am. Chem. Soc. 2014, 136, 14570.

[92] J. Kim, S.-H. Lee, J. H. Lee, K.-H. Hong, J. Phys. Chem. Lett. 2014, 5, 1312.

[93] Q. Dong, Y. Fang, Y. Shao, P. Mulligan, J. Qiu, L. Cao, J. Huang, Science 2015, $347,967$.

[94] C. S. Ponseca, T. J. Savenije, M. Abdellah, K. Zheng, A. Yartsev, T. Pascher, T. Harlang, P. Chabera, T. Pullerits, A. Stepanov, J.-P. Wolf, V. Sundström, J. Am. Chem. Soc. 2014, 136, 5189.

[95] A. Miyata, A. Mitioglu, P. Plochocka, O. Portugall, J. T.-W. Wang, S. D. Stranks, H. J. Snaith, R. J. Nicholas, Nat. Physics 2015, 11, 582.

[96] V. D’innocenzo, G. Grancini, M. J. Alcocer, A. R. S. Kandada, S. D. Stranks, M. M. Lee, G. Lanzani, H. J. Snaith, A. Petrozza, Nat. Commun. 2014, 5, 3586. 


\section{Reference}

[97] W. Rehman, R. L. Milot, G. E. Eperon, C. Wehrenfennig, J. L. Boland, H. J. Snaith, M. B. Johnston, L. M. Herz, Adv. Mater. 2015, 27, 7938.

[98] M. B. Johnston, L. M. Herz, Acc. Chem. Res. 2016, 49, 146.

[99] C. Wehrenfennig, G. E. Eperon, M. B. Johnston, H. J. Snaith, L. M. Herz, Adv. Mater. 2014, 26, 1584.

[100] R. L. Milot, G. E. Eperon, H. J. Snaith, M. B. Johnston, L. M. Herz, Adv. Funct. Mater. 2015, 25, 6218.

[101] X. Yang, X. Zhang, J. Deng, Z. Chu, Q. Jiang, J. Meng, P. Wang, L. Zhang, Z. Yin, J. You, Nat. Commun. 2018, 9, 570.

[102] M. Abdi-Jalebi, Z. Andaji-Garmaroudi, S. Cacovich, C. Stavrakas, B. Philippe, J. M. Richter, M. Alsari, E. P. Booker, E. M. Hutter, A. J. Pearson, S. Lilliu, T. J. Savenije, H. Rensmo, G. Divitini, C. Ducati, R. H. Friend, S. D. Stranks, Nature 2018, 555, 497. [103] Y. Shi, J. Xi, T. Lei, F. Yuan, J. Dai, C. Ran, H. Dong, B. Jiao, X. Hou, Z. Wu, ACS Appl. Mater. \& Interfaces 2018, 10, 9849.

[104] M. Abdi-Jalebi, Z. Andaji-Garmaroudi, A. J. Pearson, G. Divitini, S. Cacovich, B. Philippe, H. Rensmo, C. Ducati, R. H. Friend, S. D. Stranks, ACS Energy Lett. 2018, 3, 2671 .

[105] N. K. Noel, A. Abate, S. D. Stranks, E. S. Parrott, V. M. Burlakov, A. Goriely, H. J. Snaith, ACS Nano 2014, 8, 9815.

[106] S. Lee, J. H. Park, B. R. Lee, E. D. Jung, J. C. Yu, D. Di Nuzzo, R. H. Friend, M. H. Song, J. Phys. Chem. Lett. 2017, 8, 1784.

[107] J. C. Yu, D. W. Kim, D. B. Kim, E. D. Jung, K.-S. Lee, S. Lee, D. D. Nuzzo, J.S. Kim, M. H. Song, Nanoscale 2017, 9, 2088.

[108] B. Jiao, X. Zhu, W. Wu, H. Dong, B. Xia, J. Xi, T. Lei, X. Hou, Z. Wu, Nanoscale 2016, 8, 11084.

[109] Y. F. Ng, N. F. Jamaludin, N. Yantara, M. Li, V. K. R. Irukuvarjula, H. V. Demir, T. C. Sum, S. Mhaisalkar, N. Mathews, ACS Omega 2017, 2, 2757.

[110] J. Liang, Y. Zhang, X. Guo, Z. Gan, J. Lin, Y. Fan, X. Liu, RSC Advances 2016, 6,71070 .

[111] G. Li, Z.-K. Tan, D. Di, M. L. Lai, L. Jiang, J. H.-W. Lim, R. H. Friend, N. C. Greenham, Nano Lett. 2015, 15, 2640.

[112] Y. C. Kim, S.-D. Baek, J.-M. Myoung, J. Alloys Compd. 2019, 786, 11.

[113] C. Wu, Y. Zou, T. Wu, M. Ban, V. Pecunia, Y. Han, Q. Liu, T. Song, S. Duhm, B. Sun, Adv. Funct. Mater. 2017, 27, 1700338.

[114] S. G. R. Bade, J. Li, X. Shan, Y. Ling, Y. Tian, T. Dilbeck, T. Besara, T. Geske, H. Gao, B. Ma, ACS Nano 2015, 10, 1795.

[115] J. C. Yu, A. Y. Lee, D. B. Kim, E. D. Jung, D. W. Kim, M. H. Song, Adv. Mater. Technologies 2017, 2, 1700003. 


\section{Reference}

[116] M. Ban, Y. Zou, J. P. Rivett, Y. Yang, T. H. Thomas, Y. Tan, T. Song, X. Gao, D. Credington, F. Deschler, Nat. Commun. 2018, 9, 3892.

[117] P. Chen, Z. Xiong, X. Wu, M. Shao, X. Ma, Z.-h. Xiong, C. Gao, J. Phys. Chem. Lett. 2017, 8, 1810.

[118] H. Cho, S.-H. Jeong, M.-H. Park, Y.-H. Kim, C. Wolf, C.-L. Lee, J. H. Heo, A. Sadhanala, N. Myoung, S. Yoo, Science 2015, 350, 1222.

[119] L. Zhang, X. Yang, Q. Jiang, P. Wang, Z. Yin, X. Zhang, H. Tan, Y. Yang, M. Wei, B. R. Sutherland, E. H. Sargent, J. You, Nat. Commun. 2017, 8, 15640.

[120] K. Yan, M. Long, T. Zhang, Z. Wei, H. Chen, S. Yang, J. Xu, J. Am. Chem. Soc. 2015, 137, 4460 .

[121] X. Zhao, B. Zhang, R. Zhao, B. Yao, X. Liu, J. Liu, Z. Xie, J. Phys. Chem. Lett. 2016, 7, 4259 .

[122] J.-W. Lee, Y. J. Choi, J.-M. Yang, S. Ham, S. K. Jeon, J. Y. Lee, Y.-H. Song, E. K. Ji, D.-H. Yoon, S. Seo, ACS Nano 2017, 11, 3311.

[123] F. Ma, J. Li, W. Li, N. Lin, L. Wang, J. Qiao, Chem. Sci. 2017, 8, 800.

[124] V. Prakasam, F. Di Giacomo, R. Abbel, D. Tordera, M. Sessolo, G. Gelinck, H. J. Bolink, ACS Appl. Mater. \& Interfaces 2018, 10, 41586.

[125] Z. Xiao, R. A. Kerner, L. Zhao, N. L. Tran, K. M. Lee, T.-W. Koh, G. D. Scholes, B. P. Rand, Nat. Photon. 2017, 11, 108.

[126] L. Zhao, Y.-W. Yeh, N. L. Tran, F. Wu, Z. Xiao, R. A. Kerner, Y. L. Lin, G. D. Scholes, N. Yao, B. P. Rand, ACS Nano 2017, 11, 3957.

[127] Y. Yang, M. Yang, Z. Li, R. Crisp, K. Zhu, M. C. Beard, J. Phys. Chem. Lett. 2015, 6, 4688.

[128] X. Hong, T. Ishihara, A. Nurmikko, Phys. Rev. B 1992, 45, 6961.

[129] Y. Chen, Y. Sun, J. Peng, J. Tang, K. Zheng, Z. Liang, Adv. Mater. 2018, 30, 1703487.

[130] J. Xing, Y. Zhao, M. Askerka, L. N. Quan, X. Gong, W. Zhao, J. Zhao, H. Tan, G. Long, L. Gao, Z. Yang, O. Voznyy, J. Tang, Z.-H. Lu, Q. Xiong, E. H. Sargent, Nat. Commun. 2018, 9, 3541.

[131] M. Yuan, L. N. Quan, R. Comin, G. Walters, R. Sabatini, O. Voznyy, S. Hoogland, Y. Zhao, E. M. Beauregard, P. Kanjanaboos, Nat. Nanotech. 2016, 11, 872.

[132] P. Chen, Y. Meng, M. Ahmadi, Q. Peng, C. Gao, L. Xu, M. Shao, Z. Xiong, B. Hu, Nano Energy 2018, 50, 615.

[133] S. Ahn, M. H. Park, S. H. Jeong, Y. H. Kim, J. Park, S. Kim, H. Kim, H. Cho, C. Wolf, M. Pei, Adv. Funct. Mater. 2019, 29, 1807535.

[134] Z. Yuan, Z. Wu, S. Bai, Z. Xia, W. Xu, T. Song, H. Wu, L. Xu, J. Si, Y. Jin, B. Sun, Adv. Energy Mater. 2015, 5, 1500038. 


\section{Reference}

[135] F. Cao, H. Wang, P. Shen, X. Li, Y. Zheng, Y. Shang, J. Zhang, Z. Ning, X. Yang, Adv. Funct. Mater. 2017, 27, 1704278.

[136] Y. Zhou, C. Fuentes-Hernandez, J. Shim, J. Meyer, A. J. Giordano, H. Li, P. Winget, T. Papadopoulos, H. Cheun, J. Kim, M. Fenoll, A. Dindar, W. Haske, E. Najafabadi, T. M. Khan, H. Sojoudi, S. Barlow, S. Graham, J.-L. Brédas, S. R. Marder, A. Kahn, B. Kippelen, Science 2012, 336, 327.

[137] J. C. Yu, D. B. Kim, G. Baek, B. R. Lee, E. D. Jung, S. Lee, J. H. Chu, D. K. Lee, K. J. Choi, S. Cho, Adv. Mater. 2015, 27, 3492.

[138] N. Wang, L. Cheng, J. Si, X. Liang, Y. Jin, J. Wang, W. Huang, Appl. Phys. Lett. 2016, 108, 141102.

[139] Y.-H. Kim, H. Cho, J. H. Heo, T.-S. Kim, N. Myoung, C.-L. Lee, S. H. Im, T.-W. Lee, Adv. Mater. 2015, 27, 1248.

[140] K. Qasim, B. Wang, Y. Zhang, P. Li, Y. Wang, S. Li, S.-T. Lee, L.-S. Liao, W. Lei, Q. Bao, Adv. Funct. Mater. 2017, 27, 1606874.

[141] Y. Cheng, Q.-D. Yang, J. Xiao, Q. Xue, H.-W. Li, Z. Guan, H.-L. Yip, S.-W. Tsang, ACS Appl. Mater. \& Interfaces 2015, 7, 19986.

[142] G. E. Eperon, V. M. Burlakov, P. Docampo, A. Goriely, H. J. Snaith, Adv. Funct. Mater. 2014, 24, 151.

[143] B. S. Mashford, M. Stevenson, Z. Popovic, C. Hamilton, Z. Zhou, C. Breen, J. Steckel, V. Bulovic, M. Bawendi, S. Coe-Sullivan, P. T. Kazlas, Nat. Photon. 2013, 7, 407.

[144] X. Liang, S. Bai, X. Wang, X. Dai, F. Gao, B. Sun, Z. Ning, Z. Ye, Y. Jin, Chem. Soc. Rev. 2017, 46, 1730.

[145] J. Song, W. Hu, X.-F. Wang, G. Chen, W. Tian, T. Miyasaka, J. Mater. Chem. A 2016, 4, 8435 .

[146] S. Zhuang, X. Ma, D. Hu, X. Dong, B. Zhang, Ceram. Int. 2018, 44, 4685.

[147] R. Azmi, W. T. Hadmojo, S. Sinaga, C. L. Lee, S. C. Yoon, I. H. Jung, S. Y. Jang, Adv. Energy Mater. 2018, 8, 1701683.

[148] J. Cao, B. Wu, R. Chen, Y. Wu, Y. Hui, B. W. Mao, N. Zheng, Adv. Mater. 2018, 30, 1705596.

[149] X. Zhao, H. Shen, Y. Zhang, X. Li, X. Zhao, M. Tai, J. Li, J. Li, X. Li, H. Lin, ACS Appl. Mater. \& Interfaces 2016, 8, 7826.

[150] Y. Ke, N. Wang, D. Kong, Y. Cao, Y. He, L. Zhu, Y. Wang, C. Xue, Q. Peng, F. Gao, W. Huang, J. Wang, J. Phys. Chem. Lett. 2019, 10, 380.

[151] Y. Jiang, C. Qin, M. Cui, T. He, K. Liu, Y. Huang, M. Luo, L. Zhang, H. Xu, S. Li, Nat. Commun. 2019, 10, 1868. 


\section{Reference}

[152] H. Wang, X. Zhang, Q. Wu, F. Cao, D. Yang, Y. Shang, Z. Ning, W. Zhang, W. Zheng, Y. Yan, S. V. Kershaw, L. Zhang, A. L. Rogach, X. Yang, Nat. Commun. 2019, 10,665 .

[153] K. Miyano, M. Yanagida, N. Tripathi, Y. Shirai, J. Phys. Chem. Lett. 2016, 7, 2240 .

[154] Y. Yuan, J. Huang, Acc. Chem. Res. 2016, 49, 286.

[155] L. Zhao, J. Gao, Y. L. Lin, Y. W. Yeh, K. M. Lee, N. Yao, Y. L. Loo, B. P. Rand, Adv. Mater. 2017, 29, 1605317.

[156] W. L. Hong, Y. C. Huang, C. Y. Chang, Z. C. Zhang, H. R. Tsai, N. Y. Chang, Y. C. Chao, Adv. Mater. 2016, 28, 8029. 



\section{Publications}

The pupblications associated with this thesis have been removed for copyright reasons. For more details about these see:

http://urn.kb.se/resolve?urn=urn:nbn:se:liu:diva-157713 



\section{FACULTY OF SCIENCE AND ENGINEERING}

Linköping Studies in Science and Technology, Dissertation No. 1991, 2019 Department of Physics, Chemistry and Biology (IFM)

Linköping University

SE-581 83 Linköping, Sweden

www.liu.se

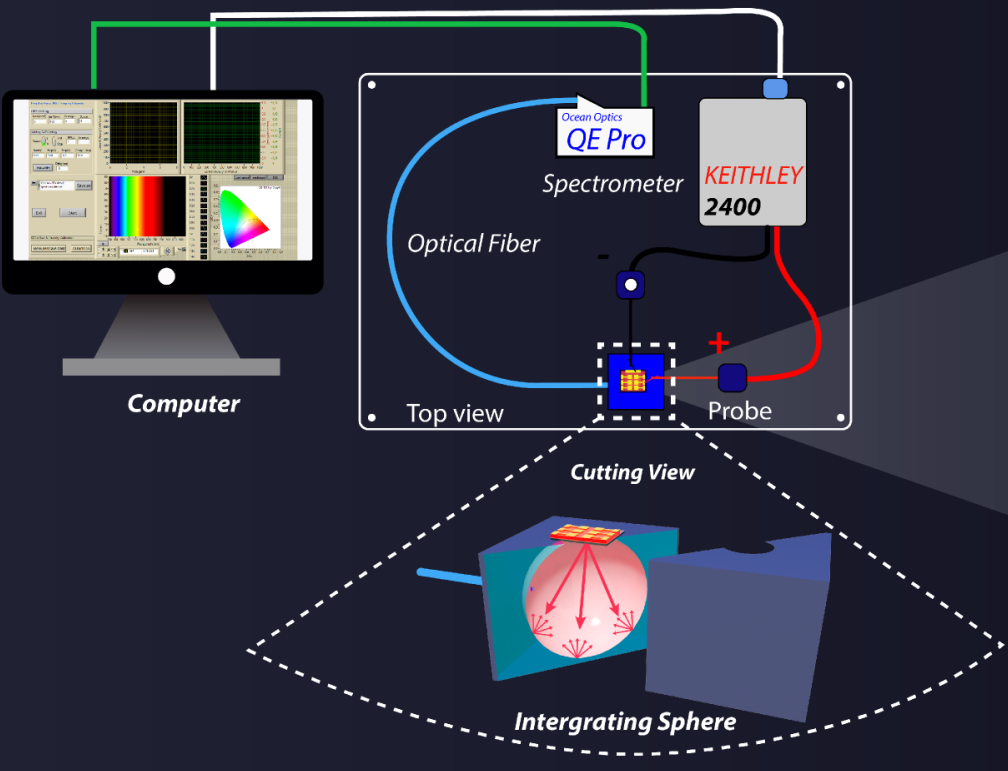

